\title{
27. Der Verleger Heinrich Beck
}

$A^{m}$

m 28. August 1973, vier Monate nach dem Tod Heinrich Becks, blickte Hans Richtscheid, seit 35 Jahren geisteswissenschaftlicher Lektor bei

C.H.Beck, auf die Lebensleistung des Verlegers zurück: «Seine Größe war, dass er mit kaufmännischem Geschick, Weltoffenheit und geistiger Aufgeschlossenheit und mit einem starken Sinn für Qualität das Erbe mehrte, das er übernommen hatte, wobei er es nicht daran fehlen ließ, auch neue Produktionsbereiche fruchtbar auszubauen. Wenn er auch ein guter Kaufmann war, so dachte er doch keineswegs nur kommerziell. Immer war er bereit, für Autoren oder Werke, die seinem Verlage Ehre machten, finanzielle Opfer zu riskieren.»1

\section{Eine Erfolgsgeschichte}

Überall, so betonte Gustav End in seiner Ansprache zu Heinrich Becks 8o. Geburtstag am 28. Februar 1969, habe Heinrich Beck «seinen Sinn für Geld und Realität» unter Beweis gestellt. «Oftmals zögernd bei vielen kleineren Verlagsvorhaben, hat er rasch zügige und weitsichtige, aber auch risikoreiche Entschlüsse gefasst in entscheidenden Fragen.» ${ }^{2}$ In der verlagseigenen Druckerei in Nördlingen waren unmittelbar nach 1945 die Voraussetzungen, den Betrieb wieder aufzunehmen, sehr günstig gewesen. ${ }^{3}$ Die Unterlagen, die Aufschluss über Herstellungskosten, Formate, typographische Angaben, Papierqualität, Bindequoten und Lagernachweise der einzelnen Beck-Titel gaben, hatten den Krieg überdauert. Seit 1946 liefen die Monotype-Bleisetzmaschinen; damals erschien, dank des erhalten gebliebenen «Stehsatzes» die 47. Auflage der Textausgabe des BGB. Wurden in diesem Jahr sechs Titel veröffentlicht, so waren es 1947 bereits 31, darunter auch die erste Nachkriegsausgabe des «Schönfelder». Sowohl die kulturwissenschaftliche als auch die juristische Produktion zogen nach der Währungsreform von 1948 kräftig an. 1949 gab es im juristischen Verlagsteil 62 Neuerscheinungen und Neuauflagen, 1950 waren es 91, 1955171. 
Im kulturwissenschaftlichen Bereich waren 194929 Neuerscheinungen und Neuauflagen zu verzeichnen, 195035 und 1955 44. Auch in den folgenden Jahren entwickelte sich die juristische Sparte dynamischer als der

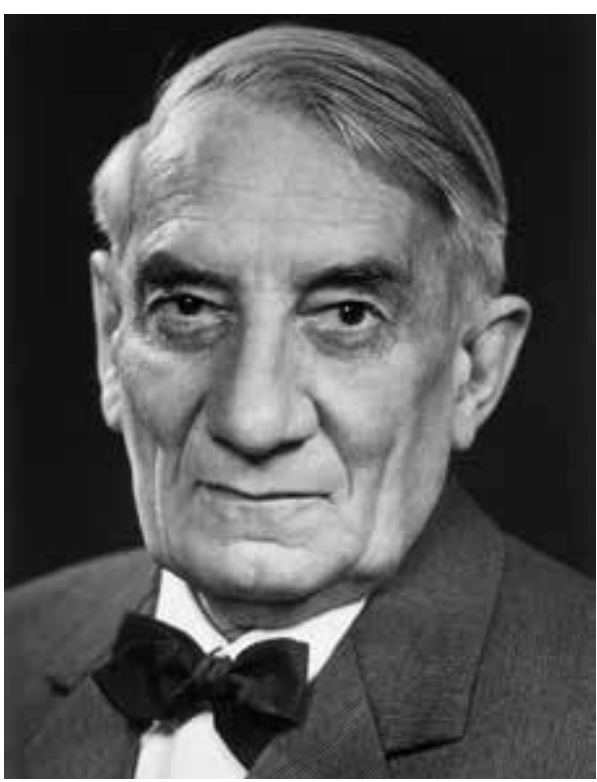

Der Verleger Heinrich Beck - ein konservativer Modernisierer kulturwissenschaftliche Verlagsteil, da die Nachfrage nach Gesetzestexten, Kommentaren, Loseblattlieferungen und Zeitschriften in der Bundesrepublik Deutschland sprunghaft anstieg. Doch auch die Zahl der literarischen und kulturwissenschaftlichen Titel (unter Einschluss der Produktion im Biederstein Verlag) entwickelte sich erfreulich: Von 1950 bis 1974 , stiegen die Neuerscheinungen und Neuauflagen von 35 auf 122. Die Auflagenzahlen bildeten dieses Wachstum um 350 Prozent nicht ab: Die Stückzahl der hergestellten Bücher stieg im selben Zeitraum von 186816 auf 411527 , d.h. um 220 Prozent. Die kontinuierliche Expansion des Unternehmens zeigt sich vor allem in der Entwicklung von Umsatz und Gewinn: $195^{\circ}$ betrug der Umsatz von C.H.Beck 56004.1 DM, 197333876044 DM, der Jahresüberschuss belief sich 1950 auf 317359 DM, 1973 auf 3626576 DM. Während sich der Umsatz mithin versechzigfachte, stieg der Gewinn um mehr als das Elffache. Auch die Druckerei in Nördlingen war erfolgreich: Der Umsatz stieg im selben Zeitraum von 960 594. DM auf 15807597 DM, der Jahresüberschuss von 32164 . DM auf 713523 DM. Allerdings verzeichnete die Gewinnentwicklung in der Druckerei keinen kontinuierlichen Zuwachs, sondern war zum Teil stärkeren branchentypischen Schwankungen unterworfen.

C.H.Beck partizipierte, wie auch andere Verlage, von $195^{\circ}$ bis 1973 an dem deutschen Wirtschaftswunder im Goldenen Zeitalter des westlichen Kapitalismus, das durch den Ausbau des tertiären Sektors - der Dienstleistungen -, den steilen Anstieg der Löhne und Gehälter, den Siegeszug der neuen Massenmedien Radio und Fernsehen, das Bekenntnis zur Westintegration und die Entstehung einer prosperierenden Konsumgesellschaft gekennzeichnet war. ${ }^{4}$ C.H.Beck trug mit dazu bei, dass München zu einem bedeutenden Buchhandelszentrum aufstieg, nachdem rasch nach dem Ende des Zweiten Weltkriegs der Exodus der Firmen aus Ostdeutschland 
eingesetzt und Leipzig seine Bedeutung als Buchmetropole verloren hatte. ${ }^{5}$ Spätestens Ende der 1950er Jahre war München der wichtigste Verlagsort der Bundesrepublik Deutschland, gut zwei Jahrzehnte stand es europaweit an der Spitze.

Die Hochkonjunkturphase der fünfziger und sechziger Jahre ging einher mit der Vergrößerung des Unternehmens. Im Jahr 1970 wurde für 14,00000 DM eine Mehrheitsbeteiligung an dem Berliner rechts- und wirtschaftswissenschaftlichen Verlag Franz Vahlen erworben, der damals gerade 100 Jahre alt geworden war; die strategische Entscheidung unterstrich die Position von C.H.Beck als Marktführer auf dem Gebiet der juristischen Literatur. ${ }^{6} 1971$ kaufte man mit J. Schweitzer eine der größten rechts- und wirtschaftswissenschaftlichen Fachbuchhandlungen der Bundesrepublik, die damals einen Jahresumsatz von fast vier Millionen DM auswies. Der Verlag und das Sortiment waren 1868 von Johann Baptist Schweitzer in Regensburg gegründet worden und 1885 nach München übersiedelt. ${ }^{7}$ Heinrich Beck hatte zum 10o-jährigen Jubiläum von J. Schweitzer betont, die Firma sei von allen Sortimentsbuchhandlungen in Deutschland die wichtigste für den Verlag geworden; C.H.Beck verdanke ihr den buchhändlerischen Erfolg der juristischen Neuerscheinungen. ${ }^{8}$

Die positive wirtschaftliche Entwicklung gestattete den großzügigen Aus- und Neubau von Verlagsgebäuden. Heinrich Beck wurde zum Bauherrn, und wie wichtig er diese Tätigkeit nahm, zeigen die zahlreichen Tagebucheinträge zu Gesprächen und Begegnungen mit seinen Architekten. «Bauen wurde zur zweiten, durchaus mit Liebe betriebenen Hauptbeschäftigung von Heinrich Beck.» ${ }^{9}$ Schon im Januar $195^{1}$ konnte der neu errichtete Verlagsbau in der Wilhelmstraße bezogen werden, im Spätherbst des Folgejahrs ein weiterer Seitenflügel. Die repräsentativen Gebäude hatte das Architektenehepaar Roderich und Katharina Fick geplant. Es folgten Um- und Neubauten in der Druckerei in Nördlingen, die bis in die zweite Hälfte der 196oer Jahre andauerten. ${ }^{10}$ Heinrich Beck ließ an seinem Wohlstand auch andere partizipieren. Er spendete großzügig für kulturelle und karitative Einrichtungen, etwa für Albert Schweitzers Tropenspital, und er unterstützte junge oder in Not geratene Autoren. Dem Privatdozenten Hans-Georg Beck half er Anfang der 195oer Jahre, indem er ihm für den geplanten Band «Kirche und theologische Literatur im byzantinischen Reich», der im Rahmen des «Handbuchs der Altertumswissenschaft» erschien, einen Vorschuss gewährte, der in Monatsraten ausgezahlt wurde. ${ }^{11}$

Zum Erfolg als Unternehmer traten persönliche Auszeichnungen und 
Ehrungen. 1954, wurde Heinrich Beck Ehrenbürger der Stadt Nördlingen. Die Philosophische Fakultät Würzburg verlieh ihm, wie schon erwähnt, im selben Jahr auf Vermittlung von Hermann Bengtson den Titel eines Dr. phil. honoris causa, die Juristische Fakultät der Ludwig-Maximilians-Universität 1959 den eines Dr. iur. honoris causa. ${ }^{12} 1961$ wurde Heinrich Beck das Große Bundesverdienstkreuz - der Verdienstorden der Bundesrepublik Deutschland - in der Staatskanzlei von Ministerpräsident Hans Ehard verliehen. ${ }^{13}$ Im Januar 1964, lud der Münchner Oberbürgermeister Hans-Jochen Vogel zu Ehren des Verlegers zu einem festlichen Essen in die Grütznerstube des Rathauses. Ende des Jahres zeichnete ihn Ministerpräsident Alfons Goppel im Bayerischen Landtag mit dem Bayerischen Verdienstorden aus. ${ }^{14}$

\section{Politisches und Persönliches}

In der Stadt München war Heinrich Beck vielfach gesellschaftlich engagiert und vernetzt. Er unterstützte als Verleger die Bayerische Akademie der Wissenschaften und die Akademie der schönen Künste, war Mitglied des Vereins der Freunde des Englischen Gartens, der Ludwig-Maximilians-Universität München, des Nationaltheaters, der Münchner Oper und des Hauses der Kunst, und er war Mitglied im Ausschuss des Deutschen Museums. An den Treffen des exklusiven Münchner Verleger-Kreises, den Rudolf Oldenbourg ins Leben gerufen hatte, nahm Heinrich Beck häufig teil. Nur griechischer Generalkonsul wollte er nicht werden, sehr zum Missfallen seiner Kinder. ${ }^{15}$

Eine Zusage gab er Roberto Rossellini, als der 1954 einen geeigneten Drehort für seinen Film «La Paura» suchte, der auf Stefan Zweigs gleichnamiger Novelle beruhte, die die «Angst» einer Ehebrecherin zum Thema hat. Von befreundeter Seite wurde Heinrich Beck gebeten, dafür seine Verlegervilla in der Klementinenstraße zur Verfügung zu stellen, die erst im Frühjahr von den amerikanischen Besatzungstruppen freigegeben worden war. Heinrich Beck willigte ein. Im August begannen die Dreharbeiten. Die Familie Beck fuhr in Urlaub. Ein fünfzigköpfiges Filmteam hielt Einzug. Ingrid Bergman, Mathias Wiemann, Edith Schultze-Westrum und Klaus Kinski standen vor der Kamera. Die Begeisterung für das Projekt des italienischen Starregisseurs verflog indes bald. Bis nachts um ein Uhr wurde gedreht, und der Lärm ließ die Leute von weither zusammenlaufen. Heinrich Beck klagte: «Sie stiegen über die Mauern und Zäune, zertrampelten die frisch angelegten Rasenflächen, und was nach Abzug dieses wil- 
den Heeres zurückblieb, war eine verwüstete Wohnstätte. Es war, wie wenn wir zweimal feindliche Besatzungen gehabt hätten.» ${ }^{16}$ Am Neujahrstag des Jahres 1955 war der Ärger über den «feindlichen Überfall» des vergangenen Sommers verflogen. Gemeinsam mit seiner Tochter Susanne ging Heinrich Beck ins Kino, um den Film zu sehen. Erfreut zeigte er sich, dass sein Haus «in Einzelheiten gut zur Wirkung» komme. Obwohl die Kritik Rossellinis Werk nicht positiv aufgenommen hatte, notierte der Verleger: «Aber der Film ist gut. Das Spiel der Bergman vorzüglich.» ${ }^{17}$

Mit lebhaftem Interesse verfolgte Heinrich Beck das politische Geschehen. Die drohenden globalen Folgen des Kalten Krieges beunruhigten ihn. Am 28. Oktober 1962 notierte er in sein Tagebuch: «Kubakrise auf dem Höhepunkt.» Einen Tag später: «Nachricht am Morgen: Chruschtschow hat nachgegeben.» ${ }^{18}$ Die Kunde von der Ermordung des amerikanischen Präsidenten John F. Kennedy erreichte ihn noch am 22. November 1963 inmitten einer privaten Feier mit Carl Hoeller und Rolf Grillmair. Schockiert schaltete man das Radio ein und verfolgte das Geschehen. Die aufgewühlte Runde saß bis spät nachts zusammen. Der letzte Eintrag an diesem Tag vermerkt die Vereidigung des Vizepräsidenten Lyndon B. Johnson. ${ }^{19}$ Informationen über den Militärputsch in Griechenland verfolgte Heinrich Beck 1967 ebenso aufmerksam wie über den Nahostkonflikt und den Sechstagekrieg. ${ }^{20}$ Im Sommerurlaub 1972 erfuhr der Verleger von der «Münchner Katastrophe», der Ermordung der israelischen Sportler «durch arabische Terroristen» während der Olympischen Spiele. ${ }^{21}$

Bundespolitisch neigte Heinrich Beck der CDU mit ihrem Kanzler Konrad Adenauer zu. Befriedigt notierte er nach den Wahlen zum dritten Deutschen Bundestag 1957 in sein Tagebuch: «Adenauer hat gesiegt.»"22 Auch die Fernsehübertragung des Staatsbegräbnisses für den Altkanzler im April ${ }_{1967}$ bewegte ihn. ${ }^{25}$ Doch war der Münchner Verleger kein bedingungsloser Gefolgsmann des rheinischen Kanzlers. Anfang der 196oer Jahre ging Heinrich Beck innerlich auf Distanz zu Adenauers Europapolitik und dem Élysée-Vertrag. Hatte er darauf gehofft, dass es eine Europäische Gemeinschaft unter Einbindung Großbritanniens gäbe, so machte in seinen Augen die Achse Bonn-Paris dies unmöglich: De Gaulle durchkreuze solche Pläne einer weitergehenden politischen Integration Europas. Adenauer fahre nach Paris und schließe mit de Gaulle einen «Freundschaftsbund», dessen Konsequenzen schwer abzusehen seien. «Wenn wir noch Fürsten hätten», bemerkte er in einem Brief an Albert Schweitzer, «die eine persönliche Freundschafts- und Eifersuchtspolitik trieben, wäre es kaum anders.» ${ }^{24}$ 
In Bayern wählte Heinrich Beck die CSU oder die F.D.P. ${ }^{25}$ Mit Unverständnis reagierte er auf die Proteste der studentischen Jugend nach 1968. Demonstrationen gegen den Vietnamkrieg und die Ausweitung der amerikanischen Kriegführung, die 1970 auf Kambodscha ausgriff, ärgerten ihn, da solche «Propagandamärsche» mit Verkehrsbehinderungen einhergingen. ${ }^{26}$

Den konservativen Habitus des Verlegers charakterisierte Heimito von Doderer. Den «Bestand der Sachen» ändere er nicht; «seiner Funktion nach erbt er und bewahrt er». ${ }^{27}$ Die Devise «Keine Experimente», die die CDU im Bundestagswahlkampf des Jahres 1957 ausgegeben hatte, machte sich der Bürger Heinrich Beck zu eigen. Skeptisch beurteilte er den raschen Wandel der fünfziger Jahre: «Niemand weiß, wie lange die alten Einrichtungen und Lebensformen noch Bestand haben», schrieb er 1958 an eine alte Freundin der Familie. ${ }^{28}$ Doch als Unternehmer war er wesentlich risikofreudiger, als diese Beschreibung erahnen lässt.

Zwei weitere Tugenden charakterisierten den Verleger, die seiner protestantischen Sozialisation geschuldet waren: Sparsamkeit und Pflichtbewusstsein. Während für die Verlagsneubauten hohe Summen aufgewendet wurden und sich Heinrich Beck, wie noch deutlich werden wird, bei Zulagen und Geschenken an seine Mitarbeiterinnen und Mitarbeiter meist großzügig zeigte, war die persönliche Lebensführung eher bescheiden. Gelegentlich vermerkte er in seinem Tagebuch selbstkritisch, dass er «geizig» sei, weil er bei privaten und betrieblichen Feiern übertrieben spare. So konnte es vorkommen, dass an Silvester «beim Prosten um Mitternacht» nur noch «ein minimaler Rest in den Gläsern» war. Beim «Tanztee» im Verlag wiederum gab es «Bowle mit Fruchtsekt», die «billig und gut» war, auch wenn sie nicht recht zu den ebenfalls servierten Weißwürsten passte. ${ }^{29}$

Die Allüren der nouveaux riches im Wirtschaftswunderland waren Heinrich Beck fremd. Nur für das bekannteste Statussymbol der bundesrepublikanischen Wohlstandsgesellschaft scheint er eine Schwäche gehabt zu haben: Die Autos mit dem Stern gefielen ihm, auch wenn er sich zugleich für das Käfer-Cabrio begeistern konnte. 1951 kaufte er - unter Nutzung der «noch geltenden Chancen der Abschreibung» - das neueste Mercedes-Modell für 13500 DM, das «als Ersatz eines in den Kriegsläuften untergegangenen angeschafft wurde». ${ }^{30}$ Mit dem Auto erfüllte sich auch der Verleger seinen zeittypischen Traum von der Freiheit und fuhr mit der Familie auf mehrwöchige Ferienreisen in den Süden. Gerne besuchte er Frankreich, dessen Landessprache er beherrschte. Nach Großbritannien hingegen zog es ihn nicht: Seine «englischen Sprechfähigkei- 
ten» waren schwach, und je älter er wurde, desto größere «Hemmungen» hatte er, sich «in diese fremde Welt zu stürzen». ${ }^{31}$

Heinrich Beck stand, wie schon in den zwanziger und dreißiger Jahren, zu der Verantwortung, die er als Verleger für seine Mitarbeiter und Autoren hatte. Also nahm er sich gefährdeter Projekte an, selbst wenn sie seinen persönlichen Überzeugungen zuwiderliefen. So überarbeitete er persönlich die Übersetzung von «Der Mensch im Kosmos», einem Hauptwerk des katholischen Theologen und Philosophen Pierre Teilhard de Chardin, das 1959 von C.H.Beck in erster Auflage veröffentlicht wurde. Zwei Jahre später folgte «Die Entstehung des Menschen». Der französische Jesuit bemühte sich um eine Verbindung von Theologie und Naturwissenschaften, von christlichem Glauben und darwinistischer Evolutionslehre, stieß aber mit seinem Unterfangen bei konservativen Vertretern der Amtskirche auf Ablehnung. Die Maßnahmen des Heiligen Offiziums gegen die Verbreitung seiner Lehren dauerten über seinen Tod hinaus und endeten erst mit dem Zweiten Vatikanischen Konzil. Dank der Übersetzungen seiner Schriften durch C.H.Beck erzielte Teilhard de Chardin auch in Deutschland zeitweise eine beträchtliche Wirkung. In der Reihe der «Beck'schen Sonderausgaben» lagen beide Werke ab 1965 bzw. 1969 in der achten bzw. fünften Auflage vor. Sie sind auch heute noch lieferbar. Der kulturprotestantische Agnostiker Heinrich Beck, der sich sein Leben lang vom Katholizismus abgrenzte und keinen katholischen Schwiegersohn haben mochte, ${ }^{32}$ half als Verleger einem jesuitischen Theologen, seine kosmische Christologie zu verbreiten, die den alten Gott der Offenbarung mit dem neuen Gott der Evolution auszusöhnen suchte. Als Horst Wiemer allerdings einen französischen Roman zur Übersetzung vorschlug, der die Schicksale eines Arbeiterpriesters erzählte, wies Heinrich Beck das Ansinnen «wegen der protestantischen Tradition» des Verlags ab. ${ }^{33}$

1956 hatte Heinrich Beck gemeinsam mit Horst Wiemer und Hans Richtscheid die Entscheidung getroffen, die zentralen Schriften des französischen Jesuiten zu übersetzen. ${ }^{34} 1958$ jedoch quälte er sich durch die Korrektur der Übersetzung von Othon Marbach. Erst war der Ärger groß, dann freute sich Heinrich Beck über die Anerkennung seiner Arbeit durch Hans Richtscheid. ${ }^{35}$ Jede freie Minute arbeitete er an den Fahnen von «Der Mensch im Kosmos», und selbst am Heiligen Abend setzte er sich an den Schreibtisch. Im neuen Jahr verfolgten ihn die Druckbogen; die immer noch notwendigen corrigenda ließen ihn fast verzweifeln. Den Romanisten Joachim Moras, der die kulturpolitische Zeitschrift «Merkur» mit herausgab, forderte Richtscheid auf, verbesserungswürdige Stellen in den 
Fahnen, die man ihm zugeschickt hatte, mitzuteilen; zugleich äußerte der Lektor die Bitte zu prüfen, ob ein Vorabdruck möglich sei. ${ }^{36}$ In letzter Minute ließ sich Heinrich Beck von paläontologischer Seite helfen, um die verbliebenen dunklen Stellen zu verstehen. ${ }^{37}$ Jahre später kommentierte Hans Richtscheid diesen Einsatz: Dass die schwierige Übersetzung von Teilhard de Chardins «Der Mensch im Kosmos» gelungen sei und Anerkennung gefunden habe, sei der intensiven Mitarbeit des Verlegers zu verdanken. Dabei habe er nicht einmal mit dem Verfasser übereingestimmt. «Denn Heinrich Beck war weniger Christ als ein Stoiker.» ${ }^{38}$ Doch nicht die stoische Tugend der apatheia als vielmehr die protestantische Ethik ließ ihn diese Pflicht tragen.

\section{Zur Programmentwicklung}

«Das Profil seines Verlags ist Gediegenheit, sein Programm ist Vielfalt», schrieb eine überregionale Tageszeitung zu Heinrich Becks 7o. Geburtstag im Jahr 1959. ${ }^{39}$ Der große Aufschwung des Verlags in den fünfziger und sechziger Jahren war vor allem der juristischen Produktion geschuldet. «Gab es noch weiße, vom Verlag nicht erschlossene Flecken in der immer weitläufigeren und komplexeren Rechtslandschaft, so wurden diese alsbald besetzt. Kein neues Rechtsgebiet von einiger Bedeutung entstand, dessen sich der Verlag nicht früher oder später angenommen hätte.» ${ }^{40} \mathrm{Im}$ juristischen Bereich fand auch die gravierendste organisatorische Veränderung statt: Die Berliner Filiale erlangte nie mehr die Bedeutung, die sie vor 1945 für den Verlag hatte, und wurde schließlich in der zweiten Hälfte der sechziger Jahre aufgelöst; ${ }^{41}$ an ihre Stelle war längst die Vertretung in Frankfurt gerückt, wo unter der Leitung von Alfred Flemming die «Neue Juristische Wochenschrift» redigiert wurde, die seit 1953 im Wochenrhythmus erschien. Die rechtswissenschaftlichen Veröffentlichungen gehörten - und gehören - zur Grundausstattung eines jeden Juristen. C.H.Beck wurde zum Marktführer, dessen Vertriebspolitik und Preisgestaltung auch für Verdruss sorgten. Bisweilen mussten Verdächtigungen entkräftet werden. So strengten sieben Referendare 1966 ein Missbrauchsaufsichtsverfahren vor dem Bundeskartellamt an, in dem sie darüber Beschwerde führten, dass sie zur Abnahme der aus ihrer Sicht teuren Ergänzungslieferungen in den Gesetzessammlungen von Schönfelder und Sartorius verpflichtet würden. ${ }^{42}$

Der Verlag richtete sein Programm nach dem Zweiten Weltkrieg konse- 
quent an den neuen politischen Gegebenheiten aus. Dies hatte inhaltliche, aber auch personelle Diskontinuitäten zur Folge. Als Ende 1948 oder Anfang 1949 der Rechtswissenschaftler Herbert Krüger, der an dem Aufbau einer nationalsozialistischen Staats- und Verwaltungsrechtslehre mitgearbeitet hatte, ${ }^{45}$ nach der Möglichkeit fragte, ob sein Buch «Volk und Staat», das ursprünglich 1945 bei C.H.Beck erscheinen sollte, nun publiziert werden könne, antwortete Georg Sund, der Verlag könne sich nicht dazu entschließen, die Sache zu übernehmen. Denn es sei im Augenblick sicher nicht der richtige Zeitpunkt, einen staatsrechtlichen Grundriss zu veröffentlichen. «Abgesehen von den Bedenken, die wir bereits damals geäußert haben - dass es nämlich schwerfallen dürfte, ein 1943/44 geschriebenes staatsrechtliches Werk den Bedürfnissen der Gegenwart durch eine bloße Überarbeitung anzupassen -, möchten wir nicht die lange Reihe theoretischer Abhandlungen auf diesem Gebiet verlängern helfen, die uns in diesem Zeitpunkt weder politisch noch juristisch weiterbringen können. Ein Kurzlehrbuch des Staatsrechtes sollte erst gebracht werden, nachdem der deutsche (vorerst leider wohl nur westdeutsche) Staat eine gewisse staatsrechtliche Konsolidierung gefunden hat, so dass dem interessierten Leser und vor allem den Studenten gewisse konkrete Tatsachen und Ergebnisse der derzeitigen staatsrechtlichen Entwicklung geboten werden können.» Vorrangig seien andere Aufgaben: «Alles ruft nach Textausgaben; viele Kurzkommentare, nach denen die Praxis besonders dringend verlangt, müssen neu aufgelegt werden; bewährte Autoren werden allmählich mit Recht ungeduldig, wenn wir die schon so lange hinausgeschobene Neuauflage ihrer Werke nicht in Angriff nehmen. Es ist unter diesen Umständen schlechterdings unmöglich, eine Arbeit zu übernehmen, von der wir eigentlich von vornherein keinen Erfolg erwarten dürfen.» ${ }^{44}$ Dies war deutlich genug. Herbert Krüger, seit 1955 Ordinarius an der Universität Hamburg, machte C.H.Beck nicht zu seinem Hausverlag.

Der Wiederaufbau des Verlags nach 1949 ging Hand in Hand mit dem Bekenntnis zur Bundesrepublik und der Abgrenzung zur Deutschen Demokratischen Republik. Die Spaltung des Landes hatte Folgen auch für die Rekrutierung der Autoren und die Weiterführung von Verträgen. Der Jurist Ernst Kaemmel, Oberregierungsrat im Reichsfinanzministerium, hatte bereits in den 1920er und 1930er Jahren verschiedene Beiträge zum Steuerrecht bei C.H.Beck veröffentlicht und nach 1945 im Spruchkammerverfahren bestätigt, dass Heinrich Beck auch im «Dritten Reich» seine Bücher verlegt habe, obwohl er mit einer Jüdin verheiratet und deshalb Repressionen ausgesetzt gewesen sei. ${ }^{45}$ Zusammen mit Friedrich Wilhelm Koch hatte 
er das Einkommens- und Bürgersteuergesetz vom 16. Oktober 1934, kommentiert. Als er Anfang der 1950er Jahre beabsichtigte, seinen Kommentar zum Steuerrecht zu überarbeiten, erhielt der ostdeutsche Finanzfachmann eine Absage. Der Verlag trat von dem Vertrag zurück und rechtfertigte diesen Schritt durch das besondere Interesse, «eine Kommentierung der wichtigsten Steuergesetze nicht von einem Autor veröffentlichen zu lassen, der als Amtsträger der Deutschen Demokratischen Republik innerhalb der Bundesrepublik nicht über die nötige Autorität verfügen kann». ${ }^{46}$

Wie sah das Programm des Verlags in den fünfziger und sechziger Jahren aus? Man setzte sowohl auf der Makroebene (der Darstellung des Gesamtverlags) wie auf der Mikroebene (der Veröffentlichung einzelner Bücher, Reihen und Zeitschriften) auf Kontinuität. C.H.Beck sollte trotz des forcierten Ausbaus der juristischen Sparte ein Universalverlag bleiben. Hans-Ulrich Büchting, ehemaliger Prokurist und langjährige Vertrauter, brachte es auf den Punkt: Heinrich Beck war an der Philosophie interessiert, überhaupt an den Geisteswissenschaften, die «Juristerei» hingegen «hielt er sich». ${ }^{47}$

Im kulturwissenschaftlichen Bereich wurden renommierte Unternehmen wie das «Handbuch der Altertumswissenschaft» fortgeführt und neue begründet. Hier ist etwa das «Handbuch der Vorgeschichte» zu nennen, das Hermann Müller-Karpe durch disziplinierte Arbeit in vier Bänden (bzw. neun Teilbänden) in erster Auflage zwischen 1966 und 1980 vorlegte. Weiter zurück reicht die groß angelegte «Geschichte der deutschen Literatur», die von Helmut de Boor und Richard Newald herausgegeben wurde. Beide hatten in der Schweiz gelehrt, der eine an der Universität Bern, der andere an der Universität Freiburg im Üechtland. Beide waren nach Ende des Krieges wegen ihrer nationalsozialistischen Agitation ausgewiesen worden und kehrten nach Deutschland zurück. ${ }^{48}$ In der Not unmittelbar nach ihrer Ausweisung hatten sie den Plan gefasst, ein literaturgeschichtliches Lehrbuch zu verfassen, das sich an Studenten richtete. Man fühlt sich an Hermann Bengtsons «Einführung in die Alte Geschichte» erinnert. Doch aus dem geplanten Kompendium entstand die mehrbändige Literaturgeschichte, zu der de Boor die ersten drei Bände zum Mittelalter (1.Aufl. 1949-1962) und Newald den fünften und sechsten Band verfasste (1.Aufl. 1951-1957, postum), die die Zeit vom «Späthumanismus» bis zur «Vorbereitung der Klassik» abdeckten. Newald starb bereits 1954, an dem Tag, als er an der Freien Universität Berlin zum Ordinarius ernannt worden war. Aber de Boor, seit 1949 ebenfalls Ordinarius an der Freien Universität, stieg auch dank dieses Standardwerks, das nach 


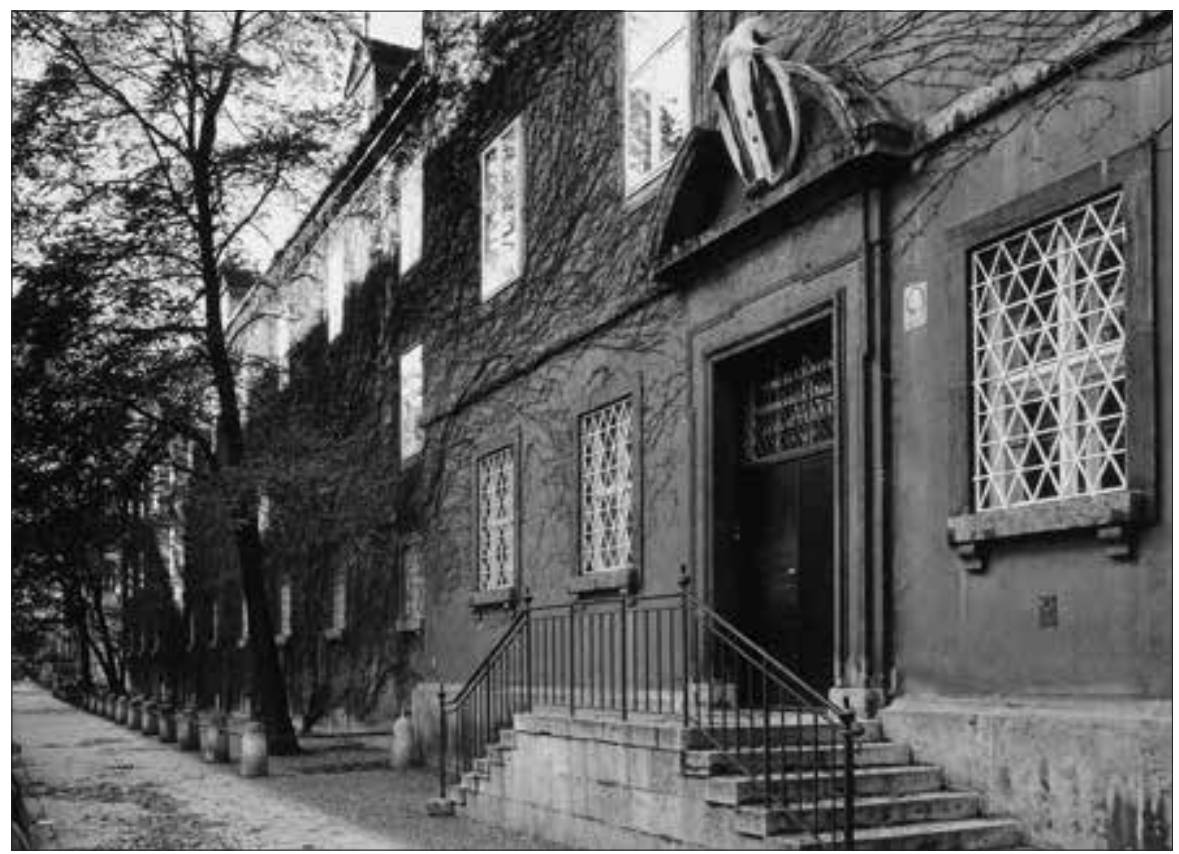

Haupteingang des Verlags in der Wilhelmstraße 9

Heinrich Beck in den 196oer Jahren «schon fast zu einem Katechismus für die heranwachsende Germanistengeneration geworden» war, ${ }^{49} \mathrm{zu}$ dem bekanntesten und einflussreichsten Altgermanisten seiner Zeit auf. Für den Verlag war es erfreulich, dass der Bedeutung des Unternehmens für die Wissenschaft auch «sein äußerer Erfolg» entsprach. ${ }^{50}$ Wie bei solchen Unternehmungen üblich, verzögerte sich das Erscheinen des einen oder anderen Bandes erheblich, die Autoren wechselten, und zwischendurch bot der Herausgeber Helmut de Boor an, sich zurückzuziehen. ${ }^{51}$ Das eindrucksvolle Monument nationalphilologischer Historiographie überlebte jedoch die Abwendung vieler Literaturwissenschaftler von der Literaturgeschichtsschreibung in den sechziger Jahren, wurde überarbeitet, modifiziert und von bekannten Germanisten wie Gerhard Schulz, Peter Sprengel, Wilfried Barner und Helmuth Kiesel bis heute fortgeführt.

Nicht minder wichtig für die Geschichts- und Kulturwissenschaften war das von Max Spindler herausgegebene «Handbuch der bayerischen Geschichte». Das Unternehmen illustrierte Spindlers innovatives Konzept einer Landesgeschichte, das er auch an seinem 1947 gegründeten Institut an der Ludwig-Maximilians-Universität München umgesetzt hatte.52 Die einzelnen Landesteile Bayerns in Vergangenheit und Gegenwart sollten 
berücksichtigt, vergleichende Betrachtungen angestellt und die Entwicklungen bis in jüngste Zeit thematisiert werden. Nicht mehr allein die politische Geschichte nahm man in den Blick. Einzelne Kapitel galten der Wirtschafts-, der Kultur- und der Sozialgeschichte. Heinrich Beck zögerte keinen Moment, das Projekt zu realisieren. Der Vertrag über das Handbuch wurde 1961 geschlossen. Energisch trieb der 1959 emeritierte Historiker das Projekt voran. Rasch wurden differenzierte Gliederungen für die einzelnen Bände ausgearbeitet und elf Mitarbeiter ausgewählt, mit denen Spindler das Handbuch realisieren wollte. Bei C.H.Beck war Georg Sund der Ansprechpartner, der auch mit den Autoren korrespondierte. Ihm folgte 1966 Ernst-Peter Wieckenberg. Erfolgreich bemühte sich der Verlag um einen Zuschuss durch das Bayerische Staatsministerium für Unterricht und Kultus, der für die Finanzierung der Autorenhonorare verwendet werden konnte. ${ }^{53}$

Dank des unermüdlichen Einsatzes des Herausgebers schritt dieses Vorhaben zügig voran. Regelmäßig berichtete Spindler über den Fortschritt der einzelnen Autoren. Bereits 1967 lag der erste Band vor. Inzwischen war abzusehen, dass der ursprüngliche Plan eines dreibändigen Werkes mit einem Gesamtumfang von 100 Bogen (à 16 Druckseiten) illusorisch war. Allein die satzreifen Manuskripte, die für den ersten Band vorgesehen waren, beanspruchten bereits 120 Bogen; man musste sie auf zwei Bände verteilen! Von den geplanten 57 ooo DM Autorenhonoraren waren damals bereits $38000 \mathrm{DM}$ ausgegeben. ${ }^{54}$ Es zeichnete sich ab, dass das Werk vier Bände würde umfassen müssen; die letzten beiden wurden in je zwei Teilbände unterteilt. 1974, lag das Handbuch erstmals vollständig vor. Über seine Bedeutung äußerte sich damals kein Geringerer als Eberhard Weis, dessen erster Band einer epochemachenden Montgelas-Biographie drei Jahre zuvor bei C.H.Beck erschienen war: Er glaube, dass dieses Handbuch «in weiten Partien zuverlässiger, inhaltsreicher und moderner ist als der deutsche Gebhardt». Um eine solche Darstellung ihrer Geschichte könnten «nicht nur alle anderen Bundesländer Bayern beneiden, sondern dies können auch große europäische Nationalstaaten tun». ${ }^{55}$ C.H.Beck vermittelte mit diesem Handbuch das Konzept einer modernen Landesgeschichtsschreibung, das in den folgenden Jahren in Lehre und Forschung auf diesem Gebiet an den Universitäten revolutionierte. Dieser Effekt wurde noch dadurch verstärkt, dass zahlreiche Mitarbeiter an dem Handbuch in der Folge Historische oder Landesgeschichtliche Lehrstühle bekleideten, insbesondere an den Universitätsneugründungen in Regensburg und Augsburg. Der Hinweis auf Heinz Angermaier, Ludwig Hammermayer, 
Andreas Kraus, Friedrich Prinz, Kurt Reindel und Wilhelm Volkert soll hier genügen. Diese Historiker schrieben wiederum für C.H.Beck - die Verlagsnetzwerke integrierten jetzt auch die Vertreter einer modernen Landesgeschichte. Diese waren und sind eingebunden in die Neuauflagen des «Handbuchs der bayerischen Geschichte», die seit den achtziger Jahren unter der Federführung von Andreas Kraus und - in jüngerer Zeit Alois Schmid erscheinen.

Ein Werk wie das Spindler'sche Handbuch stellte aber nicht nur Kontakte zu Autoren her, es schuf Prestige und lud zu Angeboten ein. Als die Stadt Nürnberg die Vorbereitungen zur Feier des Dürer-Jahrs 1971 traf, fragte sie bei C.H.Beck an, ob der Verlag bereit wäre, ein zweibändiges Werk zur Geschichte der Stadt herauszubringen. Verantwortlicher Herausgeber war der Historiker Gerhard Pfeiffer von der Universität Erlangen-Nürnberg, der dann wiederum mit weiteren Büchern Autor des Verlags wurde. Der Verhandlungspartner auf Seiten der Stadt war der Kultursenator Hermann Glaser - auch er wurde später Autor und Herausgeber bei C.H.Beck. An die «Geschichte der Stadt Nürnberg» von 1971, ergänzt durch «Nürnbergs Geschichte in Bilddokumenten», schlossen sich zahlreiche andere Stadtgeschichten an.

\section{Neue Themen}

Ein nicht minder ambitioniertes Unternehmen war Ende der 1950er Jahre auf dem Gebiet der Kunstgeschichte begonnen worden. Damals kam die im Pariser Verlag Gallimard von André Malraux und Georges Salles herausgegebene Reihe «Universum der Kunst» durch die Vermittlung von Horst Wiemer zu C.H.Beck. Die «Kunstbuchproduktion» machte Heinrich Beck Freude, und er betrieb sie «in erster Linie nicht als Verleger, sondern als Kunstliebhaber». ${ }^{56}$ Das Werk erschien gleichzeitig in mehreren Ländern und Sprachen. Innovativ war das auf Malraux zurückgehende Konzept, «sich mit gleicher Intensität allen Kulturen aller Erdteile zu widmen». ${ }^{57}$ Das Bedürfnis nach normativen Sammlungen, die den ganzen Globus erfassten, war groß, wie ein Blick auch auf andere Serien zeigt; erinnert sei nur an die Propyläen Welt- und Kunstgeschichte und die Lexika aus dem Hause Brockhaus.

Die traditionell eurozentrische Sicht der europäischen Kunstgeschichte wurde im «Universum der Kunst» zwar nicht überwunden, aber immerhin relativiert. Für die deutsche Ausgabe ließ sich der Verlag von Kurt Martin, 
dem Generaldirektor der Bayerischen Staatsgemäldesammlungen, beraten. Vorbereitende Gespräche wurden 1959 geführt. Der erste Band, «Sumer» von André Parrot, wurde 196o veröffentlicht. Ursprünglich waren sechzig Bände geplant, die alle Epochen und Räume erfassen sollten. Bis 1997 erschienen immerhin 4,2 voluminöse, reich illustrierte Darstellungen, die sich den kulturellen Errungenschaften Ozeaniens ebenso widmeten wie keltischer Kunst oder den gotischen Kathedralen. ${ }^{58}$ Die repräsentativen Bände, die in den sechziger Jahren zwischen 78 und 98 DM kosteten, propagierten gleichzeitig ein traditionelles Kunstverständnis, das zeitlosen Meisterwerken der Vergangenheit galt und die Kunstgeschichte mit Hilfe von Stilbegriffen chronologisch zu differenzieren suchte. Die Moderne interessierte nicht. Mit Vollständigkeitsanspruch, Qualität und Preis dieser Reihe orientierte sich der Verlag an einem zahlungskräftigen Bildungsbürgertum: Studienräte und Professoren, aber auch Ärzte, Rechtsanwälte, Apotheker, Architekten und Ingenieure. Für das «Universum der Kunst» wurde in der «Zeit», in der «Neuen Juristischen Wochenschrift» und in medizinischen Zeitschriften geworben. Die Reihe lief gut, viele Abonnenten wurden gewonnen, und nicht wenige Bände erlebten mindestens eine zweite Auflage. Subskriptionen wurden auf Einzelbände, aber auch auf das Gesamtwerk entgegengenommen. Die Auflagenhöhe betrug in den sechziger Jahren in der Regel 50oo. Zu den namhaften deutschen Kunsthistorikern, die im «Universum der Kunst» publizierten, gehörten Kurt Bittel («Die Hethiter»), Ludwig Heydenreich («Italienische Renaissance»), Werner Hofmann («Das entzweite Jahrhundert»), Willibald Sauerländer («Das Jahrhundert der großen Kathedralen»), und Andreas Tönnesmann («Der europäische Manierismus», zusammen mit Daniel Arasse). Ein anderes Großprojekt, das zwischen 1968 und 1973 in drei Bänden realisiert wurde, war «Die Kunst des deutschen Möbels»; das Standardwerk zur Geschichte des Kunstgewerbes wurde von Heinrich Kreisel, Kunsthistoriker und Generalkonservator des Bayerischen Landesamts für Denkmalpflege, in Zusammenarbeit mit Georg Himmelheber verfasst.

Bereits 1953 hatte C.H.Beck sich auf das Gebiet der Kunstwissenschaft begeben und damit seinen Anspruch unterstrichen, als Universalverlag auch dieses Feld zu besetzen. Damals erschien die deutsche Originalversion der «Social History of Art», die der ungarisch-deutsche Kunsthistoriker Arnold Hauser $195^{1}$ in englischer Übersetzung veröffentlicht hatte. Hauser, der 1938 vor den Nationalsozialisten aus Wien nach Großbritannien geflüchtet war, hatte schon am 2. Juli 1951 C.H.Beck sein deutsches Manuskript angeboten, das die Entwicklung der europäischen Kunst von den 
Höhlenzeichnungen der Steinzeit bis zum sowjetischen Propagandafilm nachzeichnete. ${ }^{59}$ Hauser, der Anregungen von Georg Simmel und Henri Bergson, aber auch von Ernst Troeltsch, Karl Mannheim und Max Weber aufgegriffen hatte, sah in den künstlerischen Stilen und Gattungen der einzelnen Epochen jeweils den Ausdruck spezifischer sozialer und ökonomischer Bedingungen und Prozesse. Die Geschichte der sozialen Klassen und ihrer Konflikte spiegelte sich nach seiner Auffassung in der Kunst; diese war folglich Teil der «Lebenstotalität», nicht überzeitlich, sondern zeitlich gebunden. ${ }^{60}$

Hans Richtscheid und Heinrich Beck waren gleichermaßen von diesem Werk angetan, das nicht nur durch seinen theoretischen Zugriff, sondern auch durch seine schiere Materialfülle beeindruckte. Allerdings regte man in München an, den deutschen Titel leicht zu modifizieren, da mit «Kunst» im Deutschen «meistens nur die Vorstellung der bildenden Kunst verbunden» werde, während Hauser doch «das Schwergewicht auf die Literatur» lege. ${ }^{61}$ Entsprechend lautete dann auch der Titel: «Sozialgeschichte der Kunst und Literatur». 2500 Exemplare des über 1000 Seiten starken Werkes, das zwei preisgünstige Dünndruck-Bände umfasste, wurden zunächst gedruckt. Der Preis betrug stattliche 35 DM. Als das Werk 1953 erschien, schrieb der Verleger an seinen Autor, das «bedeutende Buch» habe er «mit wirklichem Stolz» verlegt, und er hoffe, dass es Hausers Namen «bald im ganzen deutschen Sprachgebiet bekannt und berühmt machen» werde. ${ }^{62}$ Die Nachfrage war jedoch zur Enttäuschung zunächst des Autors nur schleppend. Erst allmählich fand die «Sozialgeschichte» einen größeren Leserkreis, wurde dann aber mehrfach nachgedruckt und erreichte bis 1990 eine Gesamtauflage von 70 ooo Exemplaren. Hauser zählte zur kulturwissenschaftlichen Avantgarde. Er formulierte eine theoretisch anspruchsvolle und historisch fundierte Kunst- und Literatursoziologie, deren Ziel es war, die Wechselwirkungen zwischen geschichtlicher Entwicklung und Formen des künstlerischen Ausdrucks adäquat darzustellen. Aber der Emigrant saß zwischen allen Stühlen: Für die Marxisten war er ein bürgerlicher Revisionist, für die bürgerlichen Wissenschaftler ein Adept des dialektischen Materialismus. Kein Geringerer als Ernst H. Gombrich übte an der «Sozialgeschichte der Kunst und Literatur» fundamentale Kritik. ${ }^{63}$ Auf einen Lehrstuhl in Deutschland, den ihm sein Freund Theodor W. Adorno in dieser Zeit verschaffen wollte, wurde der Außenseiter nicht berufen; er blieb in England. ${ }^{64} 1958$ ließ Hauser die «Philosophie der Kunstgeschichte» folgen, 1964 «Der Manierismus. Die Krise der Renaissance und der Ursprung der modernen Kunst» und 1974, die «Soziologie der Kunst». 
Wie schon in den zwanziger Jahren blieb C.H.Beck gegenüber neuen Ansätzen und Strömungen im wissenschaftlichen Feld aufgeschlossen. Häretiker waren durchaus willkommen. Vielleicht las der an Henri Bergsons Philosophie geschulte Verleger Hausers kunstsoziologische Konzeption «als die letzte große Sinnsuche und Sinngebung der bürgerlichen Gesellschaft». ${ }^{65}$

Doch eine andere Zeitdiagnose bewegte Heinrich Beck stärker. Am 8. Mai 1957 übersandte er seinem Starautor Albert Schweitzer, der gerade gegen die Atombombenversuche einen Aufruf veröffentlicht hatte, ein Buch, das bei C.H.Beck zu Weihnachten $195^{6}$ veröffentlicht worden war. Es war unter dem Pseudonym Günther Anders erschienen und stammte von dem Sohn des Psychologen William Stern, der einst Professor in Breslau gewesen war. Das Buch trug den Titel «Die Antiquiertheit des Menschen. Über die Seele im Zeitalter der zweiten industriellen Revolution» und behandelte «in einer zwar überpointierten, aber dafür umso geistreicheren Form die Gefahren unserer kulturellen Lage, die durch die Entwicklung der Technik heraufbeschworen worden sind». Im Schlusskapitel werde auch die Atombombe abgehandelt, zwar nicht «mit den ins Einzelne gehenden naturwissenschaftlich-medizinischen Details», die Schweitzers Appell so besonders fesselnd gemacht hätten, «aber in umso lapidarerer Form, was die Gesamtbedrohung der Menschheit betrifft». ${ }^{66}$

Der Philosoph und Essayist Günther Anders, der bei Husserl und Heidegger studiert hatte und vor dem Zweiten Weltkrieg acht Jahre mit Hannah Arendt verheiratet gewesen war, hatte bereits 1951 sein Buch «Kafka: Pro und contra» bei C.H.Beck veröffentlicht. Dies markierte den Beginn einer langjährigen Zusammenarbeit. In seinem glänzend geschriebenen Hauptwerk von 1956, dem er im Jahr 1980 einen zweiten Band folgen ließ, beschrieb Anders am Beispiel der Atombombe die wachsende Kluft zwischen technischem Fortschritt und moralischer Hilflosigkeit, zwischen wissenschaftlicher Perfektion und menschlicher Unvollkommenheit. Als Grundübel der Zeit benannte er den prometheischen Irrtum, «dass wir glauben, das, was wir können, auch zu dürfen». ${ }^{67}$ So sah Zivilisationskritik im Atomzeitalter aus. Heinrich Beck blieb seiner Faszination für kulturkritische Entwürfe auch in der Bundesrepublik treu. Er schrieb über Günther Anders an seinen alten Freund Hans Volkelt: «Es gerät ihm so unter der Feder, und es muss den Leser geradezu bekümmern, dass der Verfasser wie gebannt erscheint von den Verstrickungen der modernen Technik. Aber zweifellos sind seine Formulierungen von einer genialen Prägnanz und entbehren nicht einmal des Humors, wenn man sich frei- 
machen kann von der bleiernen Last der in dem Buch herrschenden geistigen Atmosphäre.» ${ }^{68}$

Günther Anders war in der Anti-Atomkraft-Bewegung engagiert. Heinrich Beck versicherte seinem Autor, dass sein Verlag «sich in keiner Weise an die in Bonn betriebene Außenpolitik gebunden» fühle; aber Anders' "philosophische Betrachtungen über die Atombombe» enthielten «gar nicht unmittelbar politische Richtlinien», denn auch «mit der besten Philosophie» könne man noch keine Politik machen. ${ }^{69} 1959$ veröffentlichte der Verlag Anders' «Tagebuch aus Hiroshima und Nagasaki» in der neuen Reihe «Bücher zu Fragen unserer Zeit», der späteren «Beck'schen Schwarzen Reihe BSR». 1965 folgte nach dem Eichmann-Prozess in Jerusalem «Wir Eichmannsöhne». Günther Anders legte großen Wert darauf, dass sein offener Brief an Eichmanns Sohn Klaus Eichmann «vor oder gleichzeitig» mit der deutschen Version von Hannah Arendts «Eichmann in Jerusalem» erscheine. ${ }^{70}$ Heinrich Beck signalisierte sofort das Einverständnis des Verlags, allerdings mit einem

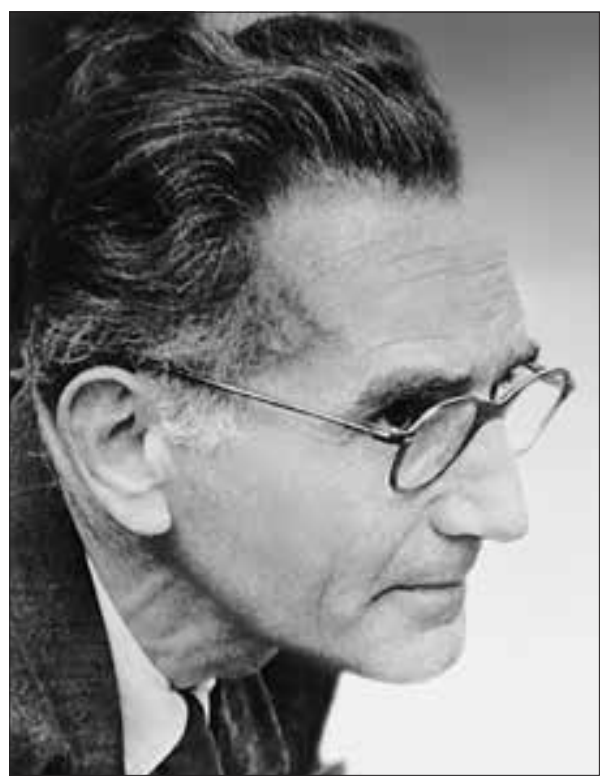

Günther Anders wahrnehmbaren inneren Vorbehalt: «Sie können sich denken, dass wir nicht dafür schwärmen, Persönlichkeiten wie Eichmann und Genossen in unserem Verlag eine Würdigung zu widmen; aber von Ihrem offenen Brief darf wohl erwartet werden, dass er, wie alle Ihre Bücher, mehr ein philosophisches Problem behandelt als ein geschichtliches, und dass für Sie dieses allgemeine Problem mit der Aburteilung Eichmanns nicht gelöst ist, sondern fortdauert.» ${ }^{71}$ Nicht veröffentlichen wollte man 1972 die Erzählungen und Gedichte, die Anders dem Biederstein Verlag anbot. Gustav End ließ den Schriftsteller wissen, dass der Verlag sein literarisches Programm stark einschränken, Lyrik nicht mehr veröffentlichen und auf Bände mit Erzählungen vorerst verzichten werde. Allerdings bot sich Gustav End an, Verbindungen zu anderen Verlagshäusern wie Luchterhand, Carl Hanser oder Suhrkamp herzustellen. Günther Anders wandte sich daraufhin direkt an Siegfried Unseld. ${ }^{72}$

Die «Bücher zu Fragen unserer Zeit» erschienen damals in schwarzem Leinen mit farbigem Aufdruck. Die Serie, die bald zur Paperback-Ausstat- 
tung überging und verlagsintern die «Schwarze Reihe» genannt wurde, wurde seit 1965 mit dieser Bezeichnung als offiziellem Titel auch der Öffentlichkeit angeboten. Darin erschienen Werke zu aktuellen Themen aus Geschichte und Politik, Philosophie und Religion, Recht und Wirtschaft, Literatur und Kunst, die sich an ein breites Publikum richteten. Ihr erster Lektor war Hans Richtscheid. Ihm folgte später der katholische Theologe Günther Schiwy, der den Jesuitenorden verlassen hatte, 1975 in Frankfurt mit einer Arbeit über die «Ideologie der Unfehlbarkeitsdiskussion» promoviert worden war und breite philosophische und literaturwissenschaftliche Interessen hatte. ${ }^{73}$ Fragen der Zeit blieben der Schwerpunkt der Reihe. 1977 wurde sie auf Taschenbuchformat verkleinert, und zehn Jahre später gab man die schwarze Grundfarbe auf. Die «Beck'sche Reihe» war geboren. Als sie sich in wechselnden bunten Farben präsentierte, war Günther Anders längst zum Vordenker der Anti-Atomkraft-, Friedens- und Ökologiebewegung geworden. ${ }^{74}$ C.H.Beck beteiligte sich mit seinen Publikationen an dem «größten und gedankenreichsten öffentlichen Diskurs der Bundesrepublik». ${ }^{75}$

\section{Ein konservativer Modernisierer}

Heinrich Beck war ein typischer Repräsentant der Verlagsbranche der frühen Bundesrepublik. Er verband in seinem Programm Altvertrautes und Neues, war, um eine Formulierung Christoph Kleßmanns zu variieren, ein Modernisierer «unter konservativen Auspizien». ${ }^{76}$ Dies führte zu - durchaus zeittypischen - Ambivalenzen, Aporien und Widersprüchen: Hausers moderne Kunstsoziologie war theoretisch innovativ, aber letztlich eurozentrisch; sie stand neben den schweren Bänden des «Universums der Kunst», die eine globale Kunstgeschichte einforderten, aber die Kunst der Vergangenheit zum Maßstab der Gegenwart erhoben. Angesichts dieses Sachverhalts scheint es geradezu grotesk, dass Heinrich Beck kurzfristig überlegte, Hausers Buch über den Manierismus in dem Sammelwerk unterzubringen. Hauser winkte ab, und es blieb bei einer selbständigen Veröffentlichung. Heinrich Beck zeigte sich nach der Lektüre der ersten Kapitel einsichtig, dass Hausers Studie im «Universum der Kunst doch vielleicht nicht am richtigen Platz wäre». ${ }^{77}$

Eine Homogenisierung des Verlagsprogramms war weder möglich noch intendiert. Manche Tradition wurde jedoch aufgegeben: Als Heinrich Beck die Aphorismen, die ihm der Komponist und Schriftsteller Hermann Wolf- 
gang von Waltershausen angeboten hatte, in einem ausführlichen Brief höflich ablehnte, bemerkte er, dass im Verlag schon seit Jahrzehnten keine Lyrik mehr erschienen sei. Verantwortlich dafür sei der Umstand, dass man «leider in keinem lyrischen, sondern in einem technischen Zeitalter lebe». ${ }^{78}$ Das Programm des Verlags erreichte nicht mehr nur, wie in den zwanziger Jahren, eine schmale bildungsbürgerliche Elite, sondern öffnete sich in den fünfziger und sechziger Jahren - einer Zeit des rasanten Wandels - der sozial durchlässigen westdeutschen «Diskussionsgesellschaft». ${ }^{79}$ C.H.Beck leistete damit einen Beitrag zur Implementierung der parlamentarischen Demokratie und zur gesellschaftlichen Verständigung über politische, soziale und kulturelle Ordnungsvorstellungen. Wesentlich stärker als in der Zwischenkriegszeit bildete das Programm eine breite Ideenströmung ab, die für eine Liberalisierung und Pluralisierung der öffentlichen Diskurse warb.

C.H.Beck profitierte in den fünfziger und vor allem in den sechziger Jahren einerseits von der sukzessiven Entstehung einer breiten Mittelstandsgesellschaft, die das alte Wirtschafts- und Bildungsbürgertum und die aufstiegsorientierten Schichten integrierte, und andererseits von dem rasanten Anstieg des Wohlstands, der trotz fortbestehender Ungleichheiten mit einer allgemeinen «Umschichtung nach oben» einherging. ${ }^{80}$ Dem Unternehmen brachten die Veränderungen in der Sozialstruktur, die Zunahme arbeitsfreier Zeiten und die Umsetzung von Bildungsreformen neue Leser; denn der nach wie vor sozial exklusive Habitus der Bürgerlichkeit konnte trotz des Erfolgs der neuen Medien - Massenpresse, Radio und Fernsehen noch nicht auf das Buch als Kulturgut verzichten. Bürgerliches Distinktionsmerkmal war und blieb der private Bücherbesitz.

Die gesellschaftlichen Veränderungen bereiteten dem Verleger jedoch Unbehagen. Anfang 1962 schrieb er an Arnold Hauser, der italienische, aber auch der französische Markt seien für aufwendig ausgestattete Bücher «viel aufnahmefähiger» als der deutsche. Denn in Italien werde «der Mittelstand und der Adel viel weniger als in Deutschland durch Steuern ausgebeutet». Man sehe, dass «in Italien fast überall die adligen Familien noch in ihren Stadtpalais sitzen, während in Deutschland solche Häuser schon lange der Privatnutzung entzogen sind». ${ }^{81}$ Der Abbau sozialer Ungleichheit nach dem Zweiten Weltkrieg verlangte in der Tat neue Publikationsformen und Distributionsstrategien. Das preisgünstige Taschenbuch war eine Antwort. Aber es war beileibe kein Erfolgsgarant.

Der Verlag C.H.Beck lebte in der öffentlichen Wahrnehmung nach wie vor von seiner Reputation als Wissenschaftsverlag: Gediegene, seriöse und 
zuverlässige Information versprachen die Bücher mit dem Greifen. Deshalb übernahm der Verlag renommierte Zeitschriften (wie den «Gnomon» oder die «Byzantinische Zeitschrift» in den Altertumswissenschaften) oder gab neue wissenschaftliche Reihen heraus. Doch gerade die Zeitschriften und Reihen trugen sich in aller Regel nicht selbst, sondern bedurften der Subvention. Hier empfahl es sich, die traditionellen Schwerpunkte zu stärken und Wildwuchs zu vermeiden. Daher wurden nicht alle Programmvorschläge, die den Verlag in den fünfziger und sechziger Jahren erreichten, umgesetzt. Man wählte sehr wohl aus: Als Dolf Sternberger im Herbst $195^{2}$ an C.H.Beck herantrat, um eine Schriftenreihe für seine Forschungsgruppe zu begründen, die sich am Alfred-Weber-Institut für Sozial- und Staatswissenschaften der Universität Heidelberg dem Studium der Parteien widmete, ließ sich der Verlag auf dieses Angebot nicht ein, obwohl der Politikwissenschaftler eine Finanzierung durch die Rockefeller-Foundation und die Bundesregierung in Aussicht stellen konnte. Als erstes Manuskript legte er die Dissertation seines Schülers Bruno Dechamps bei: «Die Verlagerung der parlamentarischen Arbeit und Entscheidung aus den Plenarversammlungen in die Ausschüsse. Ein Beitrag zur Entstehungsgeschichte der Parteifraktionen.» Gustav End formulierte die Absage für den Verlag: «Für eine Veröffentlichung in größeren Auflagen aber scheint uns ein Bedürfnis zunächst nicht vorzuliegen.» Solche Untersuchungen könnten «lediglich als Forschungsarbeiten in einigen hundert Exemplaren aufgelegt werden. Die Abnahme müsste nahezu garantiert sein, sei es nun, dass die Bundesregierung bereit ist zu einer Abnahmeverpflichtung, sei es, dass die Rockefeller-Stiftung die anfallenden Kosten übernimmt. Wir selbst können uns zur Verlagsübernahme nicht entschließen, da wir schon eine Reihe von Veröffentlichungen, die stützungsbedürftig sind, bringen.» ${ }^{82}$ Die Heidelberger Forschungsgruppe kam nicht zu C.H.Beck, und die sich allmählich formierende Politikwissenschaft fand zunächst keinen Eingang in das Programm von C.H.Beck.

\section{Eine neue Reihe}

Ein klares Profil diente der Repräsentation des Verlags, reflektierte aber auch die Selbstwahrnehmung und Selbstdarstellung der jeweiligen Fächer. C.H.Beck konnte in seinem Programm Anregungen der disziplinären Entwicklung aufgreifen, diese zugleich durch seine Publikationen verstärken oder abschwächen. Dabei kommunizierten der Verleger und seine 
Lektoren inzwischen nicht mehr notwendigerweise wie im 19. und zu Beginn des 2o. Jahrhunderts direkt mit den wissenschaftlichen Autoren, sondern delegierten diese Aufgabe - gerade bei fachwissenschaftlichen Reihen - an ein Gremium von Herausgebern, die nun auch zunehmend redaktionelle Aufgaben übernehmen mussten und dadurch die Lektoren entlasteten. Ein Beispiel aus den Altertumswissenschaften, die traditionell stark bei C.H.Beck vertreten waren, soll das soeben Gesagte exemplifizieren.

Die beiden Kieler Klassischen Philologen Erich Burck und Hans Diller hatten 1951 die Reihe «Zetemata» ins Leben gerufen. Die Neugründung verfolgte das Ziel, die Altertumswissenschaften der noch jungen Bundesrepublik Deutschland national zu integrieren und international zu repräsentieren. Der erste Band enthielt die Habilitationsschrift des Würzburger Philologen Wolf Steidle über «Sueton und die antike Biographie». Solche Reihen dienten auch der Nachwuchsrekrutierung, da zahlreiche Qualifikationsarbeiten veröffentlicht wurden. Anfang Januar 196o lehnten die Herausgeber das Manuskript des Kirchenrats Johannes Schattenmann «Studie zum Hymnus im Epheser Brief» ab, da die Untersuchung «stofflich» einem Bereich angehöre, der nicht in den «Zetemata» berücksichtigt werde und auch zukünftig keine Berücksichtigung finden sollte: «Auf das Neue Testament und rein kirchliche Literatur wollen wir in unserer Untersuchungsreihe nicht eingehen.» ${ }^{83}$ Über die gut eingeführte Reihe wurde das Konzept der Klassischen Altertumswissenschaft propagiert, wie es sich auch der Verlag zu eigen gemacht hatte. Das Fach definierte sich durch Exklusion. Auf neue Gebiete wagte man sich nicht vor.

Zu Beginn der 196oer Jahre blickte Erich Burck auf die «Zetemata» zurück. Befriedigt stellte er fest, dass sich die gut zehn Jahre alte Reihe «durchgesetzt und allgemein in der Welt Ansehen gewonnen» habe. «Auch sonst kann man ja feststellen, dass Verleger, die vor einigen Jahren noch nicht daran dachten, auf dem Gebiet der Altertumswissenschaften Publikationen herauszubringen, jetzt plötzlich auf diesem Sektor Geld und Lorbeeren ernten wollen. Da hat unser gemeinsamer Start mit den Zetemata eine ganz andere Mutprobe bedeutet, aber was nutzt es? Wir müssen mit neuen Tatsachen rechnen.» Die «neuen Tatsachen» bestanden darin, dass auch andere Verlage an dem Geschäft mit den Druckkostenzuschüssen partizipieren wollten. Burck wies Richtscheid denn auch auf «ein Konkurrenzunternehmen» hin, das der Verlag Vandenhoeck \& Ruprecht in Göttingen lanciert hatte: die Reihe «Hypomnemata», die unter anderem von Albrecht Dihle, Hartmut Erbse, Christian Habicht und Bruno Snell herausgegeben 
wurde. Der Göttinger Verlag setzte auch auf jüngere Gelehrte. Aber dies war nicht der einzige Unterschied: Vandenhoeck \& Ruprecht, so bemerkte Burck, kalkuliere offensichtlich sehr scharf und operiere «mit erheblich geringeren Zuschüssen» als C.H.Beck. ${ }^{84}$ Richtscheid klärte den gut informierten Herausgeber der «Zetemata» über die abweichenden Kalkulationen auf: «Da die Herstellungskosten wie überall andauernd steigen, ist es leider auch notwendig, immer höhere Zuschüsse zu fordern. Wir erbitten regelmäßig den Druckkostenzuschuss, der erforderlich ist, um unter Berücksichtigung des als sicher zu erwartenden Verkaufserlöses die Herstellungskosten einschließlich unserer Geschäftsunkosten zu decken. Die Geschäftsunkosten werden, wie es allgemein bei den Verlagen üblich ist, mit 4,o Prozent der Herstellungskosten angesetzt. Wir wissen aber sehr wohl, dass die Forschungsgemeinschaft bei der Bewilligung des Zuschusses die Geschäftsunkosten nur in Höhe von 15-20 Prozent der Herstellungskosten anerkennt. Wir sind deshalb von vornherein darauf gefasst, dass uns ein geringerer Zuschuss zur Verfügung gestellt wird.» Vandenhoeck \& Ruprecht habe keineswegs niedrigere Herstellungskosten als C.H.Beck, sondern erbitte eben nur den Zuschuss, den man nach den Richtlinien der Forschungsgemeinschaft auch tatsächlich erhalten könne. Richtscheid stellte nun in Aussicht, dass die Zuschussforderungen in Zukunft bei C.H.Beck ebenso berechnet würden wie bei Vandenhoeck \& Ruprecht. «Es hat ja auch keinen Sinn, dauernd mehr zu fordern, als einem aufgrund der Richtlinien der Forschungsgemeinschaft voraussichtlich zugesprochen wird. Überdies werden wir bei der Berechnung des Zuschusses einen voraussichtlichen Absatz von mindestens 300 Exemplaren, statt wie bisher in der Regel 250 Exemplaren zugrunde legen können, so dass sich ein höherer Verkaufserlös ergibt und auch dadurch die Zuschussforderung sich reduziert.» ${ }^{85}$

Die Reihen-, Zeitschrift- und Handbuchautoren nutzten ihre Kontakte zu C.H.Beck für weitere Projekte. Im Frühjahr 1962 veranstaltete Erich Burck anlässlich der Kieler Universitätstage eine Vorlesungsreihe über das Thema «Die Idee des Fortschritts in den Wissenschaften». Die Beiträge wurden 1963 in einem Band der Reihe «Bücher zu Fragen unserer Zeit» veröffentlicht. Die Auflage von Burcks Band belief sich auf 5000 Exemplare, der Preis auf DM 9,8o, und der Herausgeber erhielt ein Honorar von 10 Prozent. Der Band versammelte vor allem Aufsätze von Burcks Kieler Kollegen, aber auf Wunsch des Verlags war auch der Heidelberger Philosoph Karl Löwith vertreten. C.H.Beck half Anfang der sechziger Jahre ein fächerübergreifendes Projekt zu realisieren; mit der Unterstützung des Verlags wurde Interdisziplinarität avant la lettre praktiziert. 
Heinrich Beck lebte seinen Lektoren zwei Gebote vor: auf Qualität zu achten und die Autoren «sorgfältigst, umsichtig und liebenswürdig» zu behandeln. ${ }^{86}$ «Um viele Manuskripte bekümmerte er sich persönlich, nicht nur, indem er darin las, sondern auch, indem er korrigierte.» ${ }^{87} \mathrm{Er}$ selbst suchte den persönlichen Kontakt zu den Autoren. Zwar irritierte ihn, wenn sich Autoren seinen «guten Wein sehr schmecken» ließen, ${ }^{88}$ aber er wusste durchaus, zu welchen Gelegenheiten er großzügig sein musste. Fahrtkosten für Herausgebertreffen übernahm der Verlag. Immer wieder wurden Autoren zum Essen eingeladen, bisweilen auch Gruppen von Anwälten, Notaren und Richtern verköstigt. Zu Weihnachten wurden Buchgeschenke versandt, die Heinrich Beck für diejenigen Autoren, die ihm besonders nahestanden, selbst aussuchte. Dann konnte er sich auch über «konventionell-reizlose Weihnachtsglückwunschkarten des Verlags» ärgern. ${ }^{89}$

Von seinen Lektoren, die sich durch ein wissenschaftliches Studium für ihre Aufgabe qualifiziert hatten und im kulturwissenschaftlichen Bereich häufig auch promoviert waren, erwartete er, dass sie die klassischen Aufgaben des Berufs ausübten: ihre Autoren betreuen, Manuskripte lesen und prüfen, Informationstexte verfassen, Zeitpläne erarbeiten, Kosten kalkulieren, die Herstellung überwachen und neue Ideen entwickeln. Gewisse organisatorische Fertigkeiten und ökonomisches Handeln wurden zwar vorausgesetzt, aber nicht explizit vermittelt. Die Lektoren brachten einschlägige Kenntnisse entweder mit, eigneten sie sich an oder erhielten im Gespräch Nachhilfe. Das Ideal-, oder genauer: das Wunschbild eines Lektors entwarf Walther Killy in einem privaten Nachruf auf Georg Sund, der am 27. März 1968 nicht lange nach seinem 7o. Geburtstag gestorben war: «Gescheite Schwermut und handfester Humor, unbestechliches Urteil im Hinblick auf Menschen und Sachen, Unterordnung unter Aufgaben und Schicksale, keinerlei Ansprüche, aber doch ein sicheres, wiewohl nicht leicht erworbenes Selbstbewusstsein, wirkliche Bildung, welche nicht von sich reden macht.» ${ }^{90}$

Vor der Einrichtung einer eigenen Presseabteilung in der zweiten Hälfte der 1970er Jahre waren die Lektoren, wie schon in den Jahrzehnten zuvor, auch zuständig für die Kontakte zur Presse und insbesondere zu den Feuilletonredaktionen. Korrespondiert wurde mit allen großen Tagesund Wochenzeitungen und den einschlägigen Zeitschriften. Sukzessive wurden auch Kontakte zum Radio aufgenommen. 
Eng war die Verbindung mit dem «Merkur», der nach Ende des Zweiten Weltkriegs gegründeten «Deutschen Zeitschrift für europäisches Denken», die seit 1947 von Hans Paeschke und Joachim Moras herausgegeben wurde. Als die Zeitschrift, die bisher in der Deutschen Verlags-Anstalt erschienen war, Ende der 1950er und Anfang der 196oer Jahre einen neuen Verlag suchte, war auch C.H.Beck kurzfristig im Gespräch. Ventiliert wurde damals auch die Idee einer Kooperation zweier Verlage. ${ }^{91}$ Schließlich wechselte die Zeitschrift erst zu Kiepenheuer \& Witsch und dann zu Ernst Klett. In dem kulturpolitischen Organ sollten Bücher besprochen, Vorabdrucke veröffentlicht und Artikel, die sich auf Verlagspublikationen bezogen, lanciert werden. Hans Richtscheid korrespondierte in den fünfziger Jahren regelmäßig mit Joachim Moras. ${ }^{92}$ Man hoffte, durch dieses Organ das liberale Bürgertum zu erreichen. Für die Werke Teilhard de Chardins, Egon Friedells, Günther Anders' und Arnold Hausers wurde auf diese Weise Werbung gemacht. Während Heinrich Beck Günther Anders aufforderte, im «Merkur» zu veröffentlichen, verständigte sich Hans Richtscheid direkt mit der Zeitschrift. ${ }^{93}$ Hans Paeschke wiederum konnte 1961 gewonnen werden, einen Text, der auf Anders' «Antiquiertheit des Menschen» Bezug nahm, für den Wiederabdruck in einem Werbeprospekt freizugeben. ${ }^{94}$ Carl Schneiders «Geistesgeschichte des antiken Christentums» (1954), Ludwig Reiners’ «In Europa gehen die Lichter aus» (1954), Hugo Fischers «Die Aktualität Plotins» (1956), Stewart Perownes «Hadrian» (1966), Steven Runcimans «Die Eroberung Konstantinopels» (1966), Walther Killys «Bildungsfragen» (1971) und Richard Schmids «Das Unbehagen an der Justiz» (1975) wurden im «Merkur» angezeigt. Selbst der Eröffnungsvortrag über «Strafrecht in einer offenen Gesellschaft», den Adolf Arndt auf dem 47. Deutschen Juristentag hielt, wurde im «Merkur» vorab veröffentlicht. ${ }^{95}$ Häufig erinnerte der Verlag an ausstehende Rezensionen. 1965 klagte man: «Sie werden verstehen, dass wir natürlich sehr daran interessiert sind, unsere Bücher in Ihrem Blatt rezensiert zu sehen, dass wir aber nicht immer wieder und zum Teil recht teure Bücher schicken können, wenn nur eine geringe Aussicht besteht, eines Tages auch eine Besprechung zu erhalten.» ${ }^{96} 1970$ zählte man im Verlag 27 Bücher, die nicht besprochen worden waren. ${ }^{97}$

Die Lektoren wurden angehalten, von Gesprächen im Verlag ausführliche Protokolle anzufertigen, die sie Heinrich Beck zukommen ließen, wenn der Verleger verhindert war und die Besucher selbst nicht treffen konnte. Am 25. April 1957 schilderte Georg Sund ein Treffen mit dem Mainzer Klassischen Philologen Walter Marg, der die Redaktion des altertums- 
wissenschaftlichen Rezensionsorgans «Gnomon» führte. Er rief am Vortag überraschend bei Sund privat an, um ihm mitzuteilen, dass er gemeinsam mit Carl Schneider, einem Verlagsautor, und dessen Sohn, einem Biologiestudenten im fünften Semester, in München eingetroffen sei. Marg fragte nach einer Unterkunft, die sehr billig sein müsse, da sie nach einer längeren Reise im Mittelmeerraum «völlig abgebrannt» seien. Offenbar hoffte das Trio, dass der Verlag sie unterbringe. Als dies nicht eintrat, stellte sich heraus, dass die Reisenden doch noch ganz gut bei Kasse waren. Sund brachte sie in einem Hotel in Schwabing unter und traf sich mit ihnen dort zum Abendessen. Gegen halb zehn kam Hans Richtscheid hinzu. Die «Herren» hatten, «wohl etwas reisemüde», nicht viel Positives zu berichten. «Nach Kleinasien sind sie nicht gelangt, doch hat Professor Schneider auch in Süditalien (Groß-Griechenland) wichtige Eindrücke für die geplante Kulturgeschichte des Hellenismus empfangen. Mittels ihres Autos, eines Kombiwagens, haben sie in Griechenland auch alle Nebenplätze leicht aufsuchen können. In ihren Anschauungen waren die beiden Herren oft recht gegensätzlich. Sie widersprachen einander immer wieder, z. B. bei der Beurteilung der in Athen wieder aufgebauten und antik-modern, modernantik bunt bemalten Halle. Herrn Prof. Schneider genügen die Trümmer, Prof. Marg ist für solche Rekonstruktionen. Der Wein hat ihnen nicht geschmeckt, der Kaffee hat ihnen nicht recht geschmeckt, die Menschen in den großen und kleinen Städten haben ihnen nicht gefallen, das Wetter war durchaus nicht südlich. Die Reise durch Kleinasien will Herr Prof. Schneider nun im Herbst machen. Er hat so lange den ihm dafür gewährten Vorschuss von DM 2000 im Verlag wieder deponiert. Die drei Herren mussten München heute schon frühzeitig verlassen, konnten Ihnen im Verlag also keinen Besuch mehr machen. Sie lassen sich Ihnen bestens empfehlen.» ${ }^{98}$

Der Umgang der Lektoren mit einzelnen Autoren und Herausgebern war vertraut. Diese verstanden durchaus, ihre Privilegien, über die sie verfügten oder zu verfügen glaubten, mehr oder weniger deutlich einzufordern. Damit legten sie die Ambivalenzen offen, die den Beruf des Lektors charakterisieren und die sich daraus ergeben, dass er zwischen Autor und Verleger vermitteln und beider Interessen berücksichtigen muss. ${ }^{99}$ In den fünfziger Jahren war es in einem Verlag wie C.H.Beck den Lektoren noch möglich, ein traditionelles Berufsbild zu pflegen, das mit ihrem Selbstverständnis als wissenschaftlichem Verlagsmitarbeiter korrespondierte und eine besondere Nähe zu den Gelehrten erlaubte, die sich auch auf den privaten Kontakt erstreckte. Die fortschreitende Kommerzialisierung des 
Buchmarktes seit den 196oer Jahren veränderte das Berufsbild, zu dem zwar weiterhin die enge Betreuung der Autoren und ihrer Manuskripte gehörte, das aber auch weitergehende Organisationsfähigkeiten und Managementqualifikationen zu integrieren zwang.

\section{Personalführung}

Wer war für das Verlagsprogramm in den fünfziger und sechziger Jahren verantwortlich? Die Lektoren warben Autoren, berieten, ermunterten, warnten und trösteten sie. Über Georg Sund hieß es in einem Nachruf: Er «hat die Schriften der Bayerischen Akademie betreut, aber auch die von Reiners; er hatte den «Ewigen Brunnen` zum Fließen gebracht, aber auch die große Kepler-Ausgabe realisiert; er besorgte das «Handbuch der Altertumswissenschaft> mit der gleichen Intensität wie die große LesskowÜbersetzung Johannes von Guenthers; die ‘Deutsche Literatur, Texte und Zeugnisse> gäbe es nicht ohne ihn.» ${ }^{100}$ Der Verleger hielt sich zurück, stand sich manchmal auch selbst im Weg. Als Golo Mann Ende Juli 1968 in der Münchner Akademie der Schönen Künste einen Vortrag hielt, drängte ihn seine Tochter Susanne, den berühmten Historiker anzusprechen. Doch Heinrich Beck war an diesem Tag «gar nicht in solch selbstbewusster Stimmung». Da Golo Mann auch «etwas verschüchtert war», kamen beide nicht zusammen. ${ }^{101}$

Wie wurde im Verlag entschieden? Die Beschreibungen der Lektoren sind übereinstimmend. Heinrich Beck «war als Verleger nicht impulsiv, das heißt im wahren Sinn des Wortes: es gingen von ihm keine Anstöße auf Autoren und Lektoren aus, kaum einmal Anregungen». ${ }^{102}$ Er gab «in seiner Liberalität seinen Mitarbeitern einen Freipass an die Hand». Er wartete auf Initiativen aus dem Lektorat. Doch die letzte Entscheidung lag bei dem Verleger, der «hartnäckig» an seiner Meinung festhalten und «mit großer Zähigkeit» seinen Standpunkt verfechten konnte. Das Institut der Lektoratskonferenz gab es nicht. Wenn man sich dennoch in größerer Runde traf, schwieg der Verleger meist. Danach sprach er im kleinsten Kreis «sehr präzise zur Sache». Den Ausschlag gab das Einzelgespräch mit den Lektoren Hans Richtscheid, Georg Sund oder Horst Wiemer, mit Carl Hoeller, Herbert Thiele-Fredersdorf, Hans-Ulrich Büchting, aber auch mit Rolf Grillmair und Albert Heinrich, die für die kaufmännische und technische Leitung der Verlagsgeschäfte verantwortlich waren. Dann kam es vor, dass er «ganz freimütig» bekannte, dass er dieses oder jenes Buch nicht 
möge oder nicht verstehe. ${ }^{103}$ Gustav End und Horst Wiemer ließ er wissen, dass ihn die Übersetzung des Romans «Zeitplan» von Michel Butor, durch die er sich zuvor gequält hatte, «abscheulich» anmute, aber auch das Werk selbst wirke «wie das Produkt eines Geistesgestörten». Das Werk erschien im Biederstein Verlag. ${ }^{104}$ In einer «langen, etwas aufreibenden Debatte» widersetzte er sich Wiemers Idee, eine Reihe billiger illustrierter Bücher von Gallimard zu übernehmen. ${ }^{105}$ Scharf widersprach er, als Wiemer einen Band mit moderner russischer Lyrik herausbringen wollte. ${ }^{106}$ Es scheint, als hätten die Lektoren nach 1945 weniger Bewegungsfreiheit genossen als Walther Eggert-Windegg und August Albers in den zwanziger Jahren. Aber der Verleger war nun auch kein greenhorn mehr. Die Entscheidungsprozesse waren jedenfalls wenig institutionalisiert und integrierten in der Regel nur einen exklusiven Mitarbeiterstab. Dies ermöglichte es externen Gutachtern, aufgrund ihrer Nähe zum Verleger einen relativ großen Einfluss auszuüben, wie im Weiteren noch deutlich werden soll.

Im Verlag wuchs die Zahl der Mitarbeiter von 57 im Jahr 1950 auf 136 im Jahr 1960 und auf $182 \mathrm{im}$ Jahr 1970. Zwischen 1960 und 1970 stieg der Anteil der Teilzeitarbeitenden von zwei auf 15 Prozent; parallel dazu fiel der Anteil der männlichen Mitarbeiter von 51 Prozent (1950) auf 40 Prozent (1970). Die Entwicklung spiegelt nicht allein die wirtschaftliche Prosperität des Unternehmens, sondern auch die zunehmende gesellschaftliche Akzeptanz berufstätiger Frauen. Weibliche Beschäftigte wurden zudem nicht mehr nur als Sekretärinnen eingesetzt, sondern auch im Lektorat.

Der Verlag bezahlte seine Mitarbeitenden übertariflich. So konnte Heinrich Beck 1959 erfreut notieren, dass die «Bescherung» im Verlag wegen «anständiger» Gehaltserhöhung bei besonders guter Stimmung verlaufen sei. ${ }^{107}$ Seit Einführung des Betriebsverfassungsgesetzes im Oktober $195^{2}$ gab es in dem Münchner Verlag einen Betriebsrat, ebenso wie in der Nördlinger Druckerei. Als erster Vorsitzender in München wurde Hans Richtscheid gewählt. Die Umsetzung der betrieblichen Mitbestimmung seit den fünfziger Jahren erwies sich nicht als schwierig, da der Verleger in aller Regel Wert auf ein gutes Verhältnis zum Betriebsrat legte und die dort versammelten Lektoren und Mitarbeiter aufgrund ihrer engen Bindung an C.H.Beck nicht «auf Umsturz sannen`. Die Bereitschaft, Mitglied einer Gewerkschaft zu werden, war zudem unter den Verlagsmitarbeitenden nicht allzu stark ausgeprägt. Erst in den siebziger Jahren kam es beim Aufbau einer betrieblichen Altersversorgung wie auch in anderen Unternehmen zu Spannungen. Aber auch darüber konnte eine Einigung erzielt werden. ${ }^{108}$ Konfliktträchtiger war und ist das Verhältnis zwischen Unterneh- 
mensleitung und Betriebsräten in der Druckerei in Nördlingen: Der Grad gewerkschaftlicher Organisation ist branchentypisch wesentlich höher, die Gehälter sind niedriger und die Konfliktfelder zahlreicher.

Die Integration der Münchner Belegschaft vollzog sich durch ritualisierte Zusammenkünfte und gemeinsame Feste. Zu seinen Verlegerpflichten zählte Heinrich Beck die genaue Vorbereitung der Weihnachtsfeiern in München und der jährlichen Betriebsausflüge, die seit Mitte der 1950er Jahre in die nähere Umgebung, bisweilen auch nach Nördlingen führten. Die Weihnachtsgeschenke suchte er anfänglich selbst aus. Meist am 23. Dezember erhielten die Männer Zigarren und Wein, die Frauen individuelle Präsente. Zu Ostern wurden im Verlag Ostereier verteilt. Bis in die sechziger Jahre feierte man «Verlagsfasching». Heinrich Beck folgte Wilhelm Busch: «Auch uns, in Ehren sei's gesagt, / Hat einst der Karneval behagt, / Besonders und zu allermeist / In einer Stadt, die München heißt.» Im Verlag war am Faschingsdienstag um ein Uhr mittags Geschäftsschluss, es gab eine Fasnachtspredigt, der «geschäftsführende Klassensekretär der Närrischen Akademie der Riesenhaften» meldete sich zu Wort, die Hauspostille «Der Schwabinger Bach» verbreitete gute Laune, und alles stand unter dem Motto: «Es wird nichts krumm genommen!» Man war ausgelassen und tanzte bis in die Morgenstunden. Anfang der fünfziger Jahre traf sich die Belegschaft mehrmals am Chinesischen Turm im Englischen Garten. Heinrich Beck machte sich Gedanken über sein Kostüm, sorgte sich um die Dekoration und trat 1953 im Gewand von Antoine Watteaus «Gilles» auf. Als Harlekin mit französischem Akzent verulkte er vor 180 Verlagsmitarbeitern und Gästen seine juristischen Veröffentlichungen: Der Biederstein Verlag mache die besseren Bücher, und sein Direktor sei Horst Wiemer. ${ }^{109}$

Heinrich Beck war ein Patriarch. Im Verlag hieß er seit Anfang der sechziger Jahre, als sein Sohn Hans Dieter in das Unternehmen eintrat, respektvoll «der alte Herr». Er galt als «leise, zivil, bei recht freiem Geiste». ${ }^{110}$ An den einzelnen Standorten des Verlags außerhalb von München hatte er jeweils 〈Vertrauenspersonen`: Paul Ebel in Berlin, Alfred Flemming in Frankfurt, Georg Heydolph und später Wilhelm Wachter in Nördlingen. Personelle Kontinuität im Verlag war ihm wichtig. Heinrich Beck unterhielt zu vielen Mitarbeitern ein enges Verhältnis. Konflikte waren selten. In den fünfziger Jahren gab es Diskussionen über den Status des Biederstein Verlags. Vor allem Gehaltsforderungen von Horst Wiemer konnten den Verleger in Rage versetzen. Er verwies dann regelmäßig darauf, dass «aufgrund der Umsatzziffern für die belletristische Abteilung» solche Ansprü- 
che völlig unangemessen seien. ${ }^{111}$ Dabei zeigte sich Heinrich Beck großzügig bei runden Geburtstagen oder Betriebsjubiläen. Meist hielt er zu solchen Anlässen auch Ansprachen. Als Karl Schröpel 1957 seinen 70. Geburtstag beging, wurde ihm nicht nur eine Festschrift gewidmet; Heinrich Beck richtete eine große Feier aus und schenkte dem verdienten Prokuristen 2000 DM. 1958 erhielt Sund zu seinem 6o. Geburtstag 1000 DM, zwölf Flaschen Wein und einen Tulpenstrauß; 196o wurde Paul Ebel an seinem 8o. Geburtstag reich beschenkt und vier Jahre später das 40-jährige Dienstjubiläum von Georg Sund opulent begangen. Horst Wiemer wiederum überreichte der Verleger zu seinem 6o. Geburtstag 19671000 DM, und die Feier zum 65. Geburtstag von Hans Richtscheid im Jahr 1972 begann mit einem Sektempfang am Morgen und endete erst am Abend. ${ }^{112}$

\section{Das Verlagsjubiläum 1963}

Aufwendig waren die Vorbereitungen für das Verlagsjubiläum von 1963. Heinrich Beck überließ nichts dem Zufall. Anfang 1962 begann er trotz erheblicher gesundheitlicher Probleme, intensiv an der Verlagsgeschichte zu arbeiten. Er wollte das Werk seines Vaters zum 150. Jubiläum, dessen Darstellung er für die Zeit bis 1913 weitgehend übernahm, fortsetzen. Die Herausforderung lastete schwer auf ihm. Er fühlte sich überfordert und niedergeschlagen. ${ }^{113}$ Vor allem die Darstellung der Zeit des «Dritten Reiches» trieb ihn um. Seit dem Ende des Krieges und seinem Entnazifizierungsverfahren befasste er sich immer wieder mit dem Thema. Die Verstrickung des Verlags in das nationalsozialistische Unrecht beschäftigte ihn. Er archivierte einen Zeitungsausschnitt aus der «Süddeutschen Zeitung» von 1956, der Hans Globke und seiner Vergangenheit galt. ${ }^{114}$ Ein gutes Jahr später sichtete er «mit großer Anstrengung die alten Entnazifizierungsakten» und warf «das Entbehrliche» weg. ${ }^{115}$

Seit April 1962 las Heinrich Beck abends das Manuskript von Friedrich Glum «Der Nationalsozialismus. Werden und Vergehen». ${ }^{116}$ Glum war von 1922 bis 1937 Generaldirektor der Kaiser-Wilhelm-Gesellschaft gewesen und hatte 1933 Hitler als «genialen Staatsmann» begrüßt, wurde später aber zum Rücktritt aus seinem Amt gezwungen, weil er bald Mussolini dem deutschen «Führer» und einen elitären Ständestaat der Diktatur der NSDAP vorzog. Nach schwierigen Jahren im «Dritten Reich» war er von 1946 bis $195^{2}$ als Ministerialdirigent in der Bayerischen Staatskanzlei tätig, wo er das Verfassungsreferat leitete. Er konvertierte zum Katholizismus 
und trat der Christlich-Sozialen Union bei. Sein Versuch, in der MaxPlanck-Gesellschaft, der Nachfolgeorganisation der Kaiser-Wilhelm-Gesellschaft, wieder eine herausragende Rolle einzunehmen, scheiterte jedoch. ${ }^{117}$ Stattdessen hielt er Vorlesungen an der Münchner Universität. Der einstige Antidemokrat publizierte zunächst bei C.H.Beck über «Das parlamentarische Regierungssystem in Deutschland, Großbritannien und Frankreich» (1950, 2. Aufl. 1965). Glum plante ein Lehrbuch zum Nationalsozialismus, das die Jugend in die dunkelste Epoche der deutschen Geschichte einführen sollte. Heraus kam eine unvollständige, einseitige und inhaltlich fehlerhafte Abhandlung, die auf die Apologie der rechten Parteien im Jahr 1933 zielte und den Holocaust nur streifte. Hans Richtscheid konnte den Verfasser immerhin überreden, seine ungerechtfertigte Polemik gegen das große Buch des amerikanischen Historikers William L. Shirer über «The Rise and Fall of the Third Reich. A History of Nazi Germany» (1960) zu mäßigen, das 1961 in vier Bänden bei Kiepenheuer \& Witsch erschienen war. Richtscheid und Glum einigten sich, mit einem Ladenpreis unter 20 DM für eine möglichst große Verbreitung zu sorgen und auf diese Weise auf die konkurrierende Veröffentlichung zu reagieren. ${ }^{118}$

So versuchte Heinrich Beck am Vorabend des Verlagsjubiläums, die eigene Verlagsgeschichte mit einem Werk zu bewältigen, das aus der Katastrophenerfahrung heraus "Zeitgeschichte als Aufgabe» begriff, ${ }^{119}$ den Nationalsozialismus in einen größeren Epochenkontext integrierte, viel über den Aufstieg Hitlers und seiner Bewegung bot, den Unrechtsstaat als solchen aber nur schemenhaft erfasste. «Themenkreise wie das Propagandaministerium und seine Technik einer umfassenden Volksbeeinflussung, die Organisation der SS und ihres Polizeiapparates, die Reglementierung des geistigen Lebens und die Degradierung der Justiz zum Werkzeug einer erbarmungslosen Diktatur» wurden kaum angesprochen. ${ }^{120}$ Die konservative Deutung der «Ideologie des Nationalsozialismus» und die Apologie des deutschen Bürgertums durch Friedrich Glum, der aufgrund der innen- und außenpolitischen Notlage das nationalsozialistische «Unglück» zwangsläufig auf das deutsche Volk zukommen sah, überzeugten den Verleger Heinrich Beck.

Er erhielt Sukkurs von seinem Verwandten Helmut Berve, der für die Verlagsgeschichte «ausführliche Ratschläge» vor allem zur Darstellung der Entwicklung der Altertumswissenschaften gab. Der Verleger folgte aber dem Rat des Althistorikers nicht unbesehen. Statt einer thematischen Gliederung favorisierte Heinrich Beck eine chronologische: «Ich habe mich entschlossen, sie in mehrere Zeitabschnitte einzuteilen. Der Nationalsozi- 
alismus und der Krieg waren eben doch so einschneidende Ereignisse, dass es schwierig wäre, die allgemeine Verlagsentwicklung so zusammenhängend darzustellen, dass diese Einschnitte dabei übersprungen werden. Zwar mag die Sache nun etwas unübersichtlich werden für diejenigen, die die Entwicklung der einzelnen Disziplinen innerhalb der Beck'schen Verlagsgeschichte verfolgen wollen. Solchen kann man wohl nur durch das Register und durch lebende Kolumnen-Überschriften helfen. Es wird aber nicht sehr viele solche Interessenten geben. Wenn ich mir das Ganze vorstelle, so wird es jedenfalls mehr eine Familiengeschichte als etwa eine Wissenschaftsgeschichte darstellen. Das Buch wird vor allem für meine Nachfolger wichtig werden. Um eine Geschichte zu sein, darf sich die Chronologie der Ereignisse nicht in den Hintergrund schieben. Die Darstellung der Altertumswissenschaft im Verlag wird also zerfallen in die Zeit meines Vaters, in die Zeit zwischen den beiden Kriegen und in die Zeit nach 1945, die in so vieler Hinsicht einen Neubeginn bedeutet.»121

Doch mit der Verlagsgeschichte ging es nur schleppend voran. Mühsam wurden aus dem Verlagsarchiv Informationen zusammengetragen. Am Weihnachtstag 1962 notierte Heinrich Beck in sein Tagebuch: «Die neuen Bücher, und selbst die des eigenen Verlags, sehe ich nicht an. Innere Unruhe und Zeitmangel! Nur von der Vollendung der Arbeit kann Ruhe kommen!» Den größten Teil der Weihnachtspause saß er am Schreibtisch und musste dennoch am 31. Dezember feststellen, dass die Hoffnung getrogen hatte, «die Verlagsgeschichte, wenn auch ohne Biederstein Verlag, im alten Jahr abzuschließen». ${ }^{122}$ Die Drucklegung verzögerte sich immer mehr. Jürgen Fischer musste in der Herstellung «unendlich viele Stunden seiner Freizeit» opfern, damit das Buch überhaupt noch rechtzeitig erscheinen konnte. ${ }^{123}$ Von Georg Sund war Heinrich Beck enttäuscht, weil dieser das Jubiläum vernachlässigte, und überhaupt verdross ihn, dass «jeder glaubte, hineinpfuschen zu können». ${ }^{124}$ Mit Horst Wiemer und Gustav End gab es Dissens über «politisch heikle Partien», insbesondere missfiel ihnen, wie die Zeit unmittelbar nach Kriegsende dargestellt wurde, als Heinrich Beck die Lizenz verweigert und seine Privatvilla beschlagnahmt worden war. Deren «leidiges Nörgeln» ärgerte ihn, aber er revidierte «seufzend» die entsprechenden Stellen. ${ }^{125}$ Tatsache ist, dass seine eigene Biographie im «Dritten Reich» angesprochen, dass die Publikationen aus dem faschistischen Italien genannt und dass Ernst Günther Gründels «Sendung der jungen Generation» erwähnt wurden. Ob dies auf die Intervention der loyalen Mitarbeiter zurückzuführen ist, ${ }^{126}$ wissen wir nicht sicher. Aber 
Heinrich Beck quälte sich mit diesen Seiten, wie schon seine Sprache verrät. Über «Die faschistische Revolution»(1939-41) des Antisemiten Roberto Farinacci schreibt er, die «subjektiven Impulse» hätten sich als zu stark erwiesen, «um ein objektives Geschichtsbild erstehen zu lassen». ${ }^{127}$ Jede Diskussion um Gründel wird mit der Bemerkung abgewehrt, dass der Verfasser wie zahlreiche Altersgenossen ein «tragisches Schicksal» gehabt habe, «auf das jedoch hier nicht näher eingegangen werden kann». ${ }^{128}$ Anderes fehlte ganz: der Kommentar von Wilhelm Stuckart und Hans Globke zur Rassengesetzgebung (1936), Vittorio Mussolinis «Bomber über Abessinien» (1937) und Franz Seldtes «Sozialpolitik im Dritten Reich» (1938). Obwohl bereits die Satzarbeiten der Bibliographie für die Zeit von 1913 bis 1963 erledigt waren, erschien diese nicht. Heinrich Beck verhinderte, dass zum 20o-jährigen Verlagsjubiläum an diese Titel erinnert wurde. ${ }^{129}$

Intensiv besprach man den Aufbau des Almanachs, der gleichfalls zu diesem Jubiläum erschien und wie schon 1938 «Der Aquädukt» hieß, denn «wie ein Aquädukt das lebensspendende Wasser weiterleitet - zu den Behausungen der Menschen, auf die Felder, zu den Arbeitsplätzen und Maschinen -, so leitete ein Verlag die im Schrifttum verkörperte Geisteskraft über Raum und Zeit an den Ort, wo sie zu wirken vermag, zu den Pflanzstätten der Wissenschaft und zu den Herzen und Sinnen der Leser». ${ }^{130}$ Wer sollte darin vertreten sein? Wie konnte er aufgebaut sein? Wie umfangreich musste das Geleitwort sein? Sollten nur lebende Autoren aufgenommen werden? Selbst über die Gestaltung des bibliographischen Anhangs wurde diskutiert. ${ }^{131}$ Der Byzantinist Hans-Georg Beck, der einen «Byzantinischen Bilderbogen» aufblättern wollte, konnte bewegt werden, eine Anekdote zur «Judenverbrennung» zu streichen. Ein Absagebrief, der für einen anderen Beiträger bestimmt war, wurde gerade noch rechtzeitig abgefangen. ${ }^{132}$

Heinrich Beck hob im Geleitwort zwar die Vielseitigkeit hervor, die den Verlag in Vergangenheit und Gegenwart charakterisiert habe, ${ }^{133}$ aber tatsächlich war der Jubiläumsalmanach ein klares Bekenntnis zum literarischen und geisteswissenschaftlichen Profil des Verlags. Die großen Autoren und bekannten Wissenschaftler dort zu versammeln, ließ sich Heinrich Beck auch etwas kosten. Heimito von Doderer erhielt für seinen Beitrag «Tod einer Dame im Sommer» ein Honorar von 1200 DM. ${ }^{134}$ Beiträge verfassten Hans Graf von Lehndorff, Günther Anders, Walther Killy, Friedrich Baethgen, Hermann Bengtson, Karl Schefold, Ernst Buschor, Hans-Georg Beck, Kurt Martin, Arnold Hauser, Anton M. Koktanek, Oswald Spengler, Walther Kiaulehn, Hilde Spiel, Werner Klemke, Herbert Eisenreich, Hei- 
mito von Doderer, Helmut Scheffel, Michel Butor, Henri Pousseur, Robert Minder, Daniel Cory, Karl Löwith und George Santayana. Unter den Autoren fanden sich nur drei Juristen: Erich Prölss, Eduard Dreher und Theodor Maunz. Maunz versuchte in seinem Beitrag, das Vorurteil «von der Wertlosigkeit der Rechtswissenschaft» zu widerlegen. Der bibliographische Anhang begann, sozusagen programmatisch, mit den Altertumswissenschaften und schritt dann zur Geschichte, Kulturgeschichte und Politik voran. Es folgten Literatur- und Sprachwissenschaft sowie Germanistik, Theologie und Religionsgeschichte, Philosophie und Geistesgeschichte, Psychologie und Pädagogik, Musik und Kunst (einschließlich des Gesamtplans des «Universums der Kunst»), Naturwissenschaft und Mathematik sowie, an letzter Stelle, Recht und Wirtschaft. Eine gute Seite verwandte man auf das juristische Programm. Dabei wurden keine Einzeltitel genannt, vielmehr verwies man im Petitsatz summarisch auf 500 Werke aus verschiedenen Sachgebieten, gab einen Überblick über die juristischen Zeitschriften und charakterisierte nur allgemein die rechtswissenschaftliche Produktion des Verlags. Wer es genauer wissen wollte, dem wurde das spezielle Bücherverzeichnis «Recht und Wirtschaft» ans Herz gelegt. ${ }^{135}$ Dann folgten auf fünf Seiten Titel des Biederstein Verlags: in schöne Literatur und Sachbücher unterschieden.

Aufreibend war die Planung der Feier am 9. September 1963. Schon im November des Vorjahrs traf man sich zu einer ersten dreistündigen Konferenz. ${ }^{136}$ Das Programm musste erstellt, die Einladungslisten erarbeitet und die Frage der Örtlichkeiten geklärt werden. Das ganze Jahr über zogen sich die Vorbereitungen hin. Erst wollte man den Festakt im Herkulessaal der Münchner Residenz begehen, dann schlug in der letzten Juniwoche der Rektor der Universität München dem Verleger vor, sich in der Aula zu versammeln; dieser zögerte keinen Moment, das Angebot anzunehmen. ${ }^{157}$ Ende Juli fuhr Heinrich Beck in Urlaub. Zuhause organisierte Hans-Ulrich Büchting das kalte Büffet und verkostete mit Hans Dieter Beck und Carl Hoeller den Sekt. ${ }^{138}$ In der Zwischenzeit telefonierte Heinrich Beck täglich mit dem Verlag und klagte, dass «keine Urlaubsstimmung» aufkomme. ${ }^{159}$ Im August wurde die Presse informiert, die dann auch ausführlich von dem Jubiläum berichtete. Bis zuletzt sorgte sich Heinrich Beck, ob es genug Sitzplätze gäbe. Aufreibend war die Erarbeitung der Sitzordnung für den Festakt, die selbst im Familienkreis zu Spannungen führte. ${ }^{140}$ Am 6. September begannen die Feierlichkeiten im Verlag. Heinrich Beck erhielt die ersten Geschenke von seinen Mitarbeitern: eine Bougainvillea, einen Marzipan-Palandt und den «Schwabinger Bach». 
Die Stimmung «war durch das vorausgegangene Geldgeschenk sehr freudig gelockert». ${ }^{141}$

Aberhunderte von Gästen aus Wissenschaft und Politik, aus Verwaltung und Wirtschaft, aus Kunst und Literatur, aus der Verlagsbranche und den juristischen Verbänden strömten am Montag, den 9. September, um 10 Uhr in die Aula der Ludwig-Maximilians-Universität, die für den Festakt ausgesucht worden war. Man hatte den Raum so hergerichtet, dass fast 1600 Sitzplätze zur Verfügung standen. ${ }^{142}$ Der Saal schien gut gefüllt, obwohl einige Prominente in letzter Sekunde abgesagt hatten. Der Rektor eröffnete die Veranstaltung, dann ergriff der Verleger das Wort. Glückwünsche überbrachten der Bayerische Staatsminister für Unterricht und Kultus, Theodor Maunz, der Staatssekretär Arthur Bülow aus dem Bundesjustizministerium, der Vizepräsident der Bayerischen Akademie der Wissenschaften, Robert Sauer, der Kulturreferent der Stadt München, Herbert Hohenemser, und der Vorsteher des Börsenvereins des Deutschen Buchhandels, Friedrich Wittig. Den Festvortrag hielt der Althistoriker Hermann Bengtson. Zum Schluss sprach Heimito von Doderer über «Der Autor und sein Verlag». Für die musikalische Umrahmung sorgte das Münchener Kammerorchester.

Die große Veranstaltung unterstrich zum einen die Nähe des Verlags zur Wissenschaft, der zwar kein klassischer Wissenschaftsverlag war, dessen enge Verbindungen zu Universität und Akademie aber sein Profil bestimmten; denn aus den Wissenschaftlern rekrutierte sich die Mehrzahl der Autoren, deren Renommee wiederum dem gesamten Programm Glanz verlieh. Zum anderen kommunizierte das Unternehmen den überaus erfolgreichen Wiederaufbau nach dem Ende des Zweiten Weltkriegs, so dass es nun zu den bedeutendsten Verlagshäusern der Bundesrepublik Deutschland zählte, zu dessen Jubiläum «hohe Amts- und Würdenträger» ${ }^{143}$ in groBer Zahl kamen. Dass ein Althistoriker den Festvortrag hielt, war zudem ein programmatisches Bekenntnis zu den Altertumswissenschaften, dass Heimito von Doderer das Schlusswort sprach, unterstrich die Absicht, sich auch als literarischen Verlag darzustellen.

Heinrich Beck hatte seine Ansprache lange vorbereitet. ${ }^{144} \mathrm{Er}$ ließ die Geschichte des Verlags Revue passieren, streifte aber seine eigene Vergangenheit als Verleger nur kurz. Die Erinnerung an das «Dritte Reich» sollte keinen Schatten auf die Feier werfen. Zeittypisch blieb Heinrich Beck im Vagen. «Höhere Gewalt» habe das Erbe der Väter «um ein Haar vernichtet». Offen ließ er, ob damit der Bombenkrieg oder die Entnazifizierung gemeint war. Gustav End jedenfalls dankte er ausdrücklich dafür, dass er 
ihm geholfen habe, die «Schicksalswende des Jahres 1945» zu überstehen. Dann blickte er in die Zukunft, die ihm mitten im Kalten Krieg und angesichts des atomaren Wettrüstens als «dunkel verhangen» schien. Doch zukunftsfroh zitierte er das fälschlich Martin Luther zugeschriebene Wort: «Und wenn man mir sagte, dass morgen die Welt unterginge, würde ich heute noch ein Apfelbäumchen pflanzen.» Der Satz, dessen Logik sich zu überschlagen scheine, bringe die «Grundwahrheit» zum Ausdruck, dass «die menschliche Existenz sich gründet auf Vertrauen und Schaffensfreude». Das Motto der verlegerischen Arbeit gab beim 2oo-jährigen Jubiläum der protestantische Reformator vor.

Der 74-jährige Verleger, der schwere Krankheiten überstanden hatte, schloss aber mit einer Erklärung zu seiner Nachfolgeregelung: «Meine Jahre sind gezählt. Ich hoffe auf meine Söhne, von denen der ältere schon seit zwei Jahren im Verlag tätig ist, dass sie sich dem Auftrag nicht entziehen, den vor 200 Jahren das Haus Beck vom Schicksal empfangen hat.» Damit waren beide Söhne, Hans Dieter Beck und sein jüngerer Bruder Wolfgang, als Erben coram publico benannt. Die Töchter waren ebenso ausgeschlossen wie der Anspruch eines der beiden Söhne zurückgewiesen, den Verlag allein zu führen. Zugleich hatte Heinrich Beck nun auch seinen jüngeren Sohn in die Pflicht genommen.

Nach dem Abschluss der Veranstaltung gegen Mittag lud der Verleger seine Gäste zu einem Empfang in das Schloss Schleißheim. Dort musste er Hunderte Hände schütteln und Gratulationen entgegennehmen. ${ }^{145}$ Das Fest am 9. September sei von allen Teilnehmern, so schrieb Heinrich Beck einige Wochen später an Albert Schweitzer, als «ein besonderes Erlebnis» empfunden worden. ${ }^{146}$

\section{Gutachter}

Für den Verlag war in den fünfziger und frühen sechziger Jahren eine Gruppe von ‘freien Mitarbeitern` von besonderer Bedeutung: die Gutachter - und zwar sowohl für die Auswahl von für die Veröffentlichung bestimmten Werken als auch für die Finanzierung von wissenschaftlichen Zeitschriften und Reihen.

Was die Herausgeber der Zeitschriften und Reihen betrifft, so begleiteten sie die Drucklegung, versandten Korrekturen an die Autoren, verlangten Kürzungen und Überarbeitungen, verfügten über die Zuteilung von Freibzw. Rezensionsexemplaren und formulierten bisweilen auch ein Vorwort, 
wenn ihnen die Vorlage des Verfassers nicht zusagte. Sie mussten darüber hinaus aber auch Zuschüsse einwerben. Im Verlag wurde diese Aktivität genau dokumentiert. Die einschlägigen Schreiben leitete der zuständige Lektor an Heinrich Beck und in Kopie auch an die Herstellung weiter. Die Verlagskorrespondenz von Hans Richtscheid mit Erich Burck, um dieses Beispiel herauszugreifen, zeigt eindrücklich die enge Verflechtung von Herausgebern wissenschaftlicher Reihen, Fachgutachtern der 1951 (wieder-) gegründeten Deutschen Forschungsgemeinschaft (DFG) und dem Verlag C.H.Beck. Der einflussreiche Burck begutachtete nicht nur Manuskripte für die von ihm herausgegebenen «Zetemata», sondern zugleich auch für die Druckkostenzuschüsse der DFG. Diese Subventionen waren seit den 1950er Jahren eine willkommene Möglichkeit zur finanziellen Konsolidierung der Reihen. Die Zuschüsse der DFG - und seit Anfang der 196oer Jahre auch der VolkswagenStiftung - waren nicht unerheblich und beliefen sich Mitte der 1960er Jahre für die einzelnen Bände der «Zetemata» auf durchschnittlich 4700 DM pro Band. Zum Vergleich: In dieser Zeit wurde der Druck eines Bandes der «Byzantinischen Zeitschrift» mit 10 ooo DM subventioniert. Die Zeitschrift erschien in zwei Heften im Umfang von je 15 Bogen. Die Auflage belief sich auf 700 Exemplare. Der Ladenpreis betrug 58 DM. ${ }^{147}$ Durch den Zuschuss und den voraussichtlichen Erlös waren die Herstellungskosten und ein größerer Teil der Geschäftsunkosten in der Regel gedeckt. Die staatliche Alimentation reduzierte für den Verlag das Risiko eines Verlusts und vergrößerte die Chance auf wirtschaftlichen Gewinn. Heinrich Beck schrieb damals an Carl Hanser, «die Bedingungen der Forschungsgemeinschaft für die Gewährung von Druckkostenzuschüssen» hätten «in den letzten Jahren stillschweigend erhebliche Verbesserungen erfahren». Man könne nicht mehr sagen, dass dem Verlag durch solche Werke, die auf Zuschüsse angewiesen seien, ein Verlust entstehe. Es ergebe sich «sogar manchmal ein kleiner Gewinn». ${ }^{148}$

Nicht alle Reihentitel wurden indes durch Druckkostenzuschüsse finanziert, die an die Bedingung gebunden waren, dass kein Honorar gezahlt wurde. 1964, setzte sich Erich Burck für Hans Drexler ein, dessen Untersuchungen über «izenzen` am Versanfang bei Plautus» in den «Zetemata» erschienen: «Es wäre natürlich gerade in diesem Fall besonders schön, wenn einem so angesehenen und älteren Forscher in irgend einer Weise ein Gewinnanteil zufließen würde.» ${ }^{149}$ Der Verlag verzichtete in diesem Fall auf einen Zuschuss und nahm einen Verlust in Kauf. Drexler war sicherlich ein «angesehener» Spezialist für römische Metrik, aber nicht minder für seine flammenden Reden bekannt, die er zwischen 1933 und 1945 erst in 
Breslau und dann in Göttingen auf den Führerstaat gehalten hatte. ${ }^{150}$ Nach dem Krieg wurde er aus dem Universitätsdienst entlassen, und als einem der wenigen nationalsozialistisch belasteten Hochschullehrer gelang es ihm nicht, wieder eingestellt zu werden. Die alten Netzwerke halfen ihm nicht nur, eine rege Publikationstätigkeit zu entfalten, sondern verschafften ihm auch auf Kosten des Verlags ein bescheidenes Einkommen.

Auch bei der Beurteilung fremder Manuskripte spielten Netzwerke eine entscheidende Rolle. Carl Schneider, der von Erich Burck und Alfred Heuß protegiert wurde, legte 1965 das Manuskript zu einer «Kulturgeschichte des Hellenismus» vor. Der Althistoriker Heuß kannte den Neutestamentler Schneider bereits seit Ende der 1930er Jahre aus ihrer gemeinsamen Zeit an der Albertus-Universität in Königsberg. Heuß wiederum war von 1949 bis 1954 Kollege von Burck in Kiel gewesen. Die Nähe Schneiders zu den Deutschen Christen im «Dritten Reich» und seine Mitarbeit am Institut zur Erforschung und Beseitigung des jüdischen Einflusses auf das deutsche kirchliche Leben hatten zur Folge, dass er nach 1945 keinen Lehrstuhl mehr bekam. Er wurde Kulturreferent der Stadt Speyer und Leiter der Evangelischen Akademie der Pfalz. 1954, hatte er sein opus magnum bei C.H.Beck veröffentlicht, «Geistesgeschichte des antiken Christentums» in zwei Bänden. ${ }^{151}$ Das Projekt einer «Kulturgeschichte des Hellenismus» hatte Hermann Bengtson schon 1955, als er davon erfuhr, zurückhaltend beurteilt und einige Zeit später auf eine «völlig vernichtende Rezension» der «Geistesgeschichte» hingewiesen, die ein katholischer Theologe im «Jahrbuch für Antike und Christentum» veröffentlicht hatte. ${ }^{152}$ Da es Hermann Bengtson 1965 nicht möglich war, das Manuskript der «Kulturgeschichte des Hellenismus» zu begutachten, wandte sich der Verlag auf Bengtsons Empfehlung hin an dessen Schüler Hatto H. Schmitt, ebenfalls ein Spezialist für die Geschichte des Hellenismus und gerade auf dem Sprung auf ein althistorisches Ordinariat in Bonn. Schmitt hatte erhebliche Einwände und brachte so viele Korrekturen und Bemerkungen an, dass der Verlag befürchtete, der wissenschaftliche Wert der Darstellung müsse grundsätzlich in Frage gestellt werden. Schneiders neues Werk wurde dennoch bei C.H.Beck veröffentlicht. Das entscheidende Gutachten verfasste Helmut Berve, einst Heuß' akademischer Lehrer in Leipzig, der bereits $195^{2}$ Schneiders «Geistesgeschichte des antiken Christentums» wohlwollend aufgenommen, wenn auch nicht für das «Handbuch der Altertumswissenschaft» empfohlen hatte. Heinrich Beck hatte ihn als Obergutachter ins Spiel gebracht. Die beiden voluminösen Bände der «Kulturgeschichte des Hellenismus» erschienen 1967 und 1969, eine Auswahl 1975 als «Beck'sche Sonderausgabe». ${ }^{153}$ 
Helmut Berve nahm durch seine zahlreichen Gutachten über zwei Jahrzehnte nachhaltigen Einfluss auf die altertumswissenschaftliche Verlagspolitik. Er selbst war Verlagsautor. 1966 erschien anlässlich seines 7o. Geburtstags eine zweite, stark erweiterte Auflage der «Gestaltenden Kräfte der Antike», die von seinen Schülern Edmund Buchner und Peter Robert Franke herausgegeben wurde. Darin wurde auch die berüchtigte Schrift über Sparta aus dem Jahre 1937 wieder abgedruckt, in der Berve den nordischen Geist der spartanischen Herrenmenschen, ihre Rassengesetze und ihr elitäres Kriegertum gefeiert hatte. Im nächsten Jahr veröffentlichte Oswyn Murray in der führenden englischen Rezensionszeitschrift «The Classical Review» eine vernichtende Rezension, die mit «Terrible Simplificateur» überschrieben war und gleich im ersten Abschnitt auf Berves prominente Rolle in der Nazizeit abhob. ${ }^{154}$ Eine Kopie der Besprechung erreichte den Verlag, wo man die Wahrnehmung des Buches in der englischen Öffentlichkeit genau verfolgte. Möglicherweise hatte sie Berve selbst in die Wilhelmstraße geschickt. Mit Hilfe eines Wörterbuchs waren unbekannte englische Vokabeln des fremdsprachigen Textes übersetzt und zwischen die Zeilen geschrieben worden. Einleitend hatte Oswyn Murray das berühmte Wort seines Lehrers Arnaldo Momigliano zitiert, dass der Nationalsozialismus auch Intellektuelle in ein quasireligiöses System eingebunden habe, «which had its chief sanctuaries at Dachau and Auschwitz». Einen anonymen Leser veranlasste diese Bemerkung zur Charakterisierung des nach England emigrierten italienischen Althistorikers: «ein hassvoller emigrierter italienischer Jude». Die solchermaßen annotierte Rezension wurde im Juli $1967 \mathrm{zu}$ den Akten genommen. ${ }^{155}$

Wenig später gratulierte Heinrich Beck seinem entfernten Verwandten, «dem lieben Helmut», zu seinem neuen «gewichtigen Werk» über die «Tyrannis bei den Griechen». Sein letztes großes Buch, das ebenfalls bei C.H.Beck erschien, bedeutete, wie Alfred Heuß schon gesehen hatte, die «Rückkehr zu den wissenschaftlichen Anfängen» Berves, dem «Alexanderreich auf prosopographischer Grundlage». Die Studien zur griechischen Tyrannis waren kein althistorischer Beitrag zum damaligen Totalitarismusdiskurs, sondern wendeten die bereits in den zwanziger Jahren grundgelegten Prinzipien historischen Verstehens auf dieses Phänomen der Alten Welt an. Die Tyrannis war «die hybride Vergewaltigung eines sich selbst seine staatlichen Lebensformen setzenden, autonomen Gemeinwesens durch einen einzelnen machtgierigen Menschen». ${ }^{156}$ Indem Berve das 
Verhältnis von Tyrann und Polis untersuchte, griff er ein früher bereits von ihm traktiertes Thema auf, die Beziehung von großer Einzelpersönlichkeit und Gemeinschaft. Das Buch konnte der Forschung keine neuen Perspektiven öffnen. ${ }^{157}$

Abgesehen von seiner Publikationstätigkeit kommentierte Helmut Berve einzelne Manuskripte, empfahl Autoren, lehnte andere ab und erhielt bis zu seinem Tode 1979 ein monatliches Honorar von zuletzt 100 DM. ${ }^{158}$ Die umfangreiche Korrespondenz des Verlags mit Helmut Berve offenbart exemplarisch Stärken und Schwächen des Gutachtersystems in den fünfziger und sechziger Jahren. Die Gutachten waren ausführlich; sie galten in erster Linie dem wissenschaftlichen Charakter des Buches und wenn überhaupt - erst in zweiter Linie dessen Potential auf dem Buchmarkt. Wichtig war die Bewertung des mit einem Werk verbundenen Erkenntnisfortschritts. So dienten sie den einzelnen Lektoren - im Falle Berves den Lektoren Georg Sund und Ursula Pietsch - als maßgebliche Grundlage ihrer Entscheidungen. Damit monopolisierten die Fachwissenschaftler in vielen Fällen das Urteil über Aufnahme oder Ablehnung eines Buches. Allerdings wurden sie in den meisten Fällen nicht von sich aus tätig, sondern antworteten auf Anfragen des Verlags. Die Wissenschaftler sichteten folglich nicht systematisch den Markt, sondern beurteilten Manuskripte und Bücher, die mehr oder weniger zufällig an den Verlag gelangten. Ablehnungsbriefe an Autoren bedienten sich sachlicher Einwände und zitierten bisweilen aus gutachterlichen Äußerungen. Selten wurden Gutachten im Verlag diskutiert; sie wurden meist akzeptiert. Bestanden Zweifel, konnte ein zweites Gutachten in Auftrag gegeben werden. Die Autorität, die der Verlag einem Wissenschaftler zubilligte, spiegelte natürlich dessen Rang in der Zunft. Interessanterweise waren affektive Urteile häufiger als differenzierte Entscheidungen; Repräsentanten des wissenschaftlichen mainstream wurden gefördert, Außenseiter blieben häufig auf der Strecke. ${ }^{159}$

Gewiss: Helmut Berve hatte ein klares Urteil. ${ }^{160}$ Hans Drexler, so ließ er im Mai 1950 Sund wissen, sei «ein wirrer Mensch» und sein Buch über die plautinische Metrik sei «ungenießbar». Als Handbuchautor kam der Klassische Philologe damit nicht mehr in Betracht. Mal wurde einem Buch vorgehalten, die Quellen seien kritiklos genutzt, «jeder Klatsch, der sich in ihnen findet, ist als historische Wahrheit aufgenommen», mal dem Autor unterstellt, er sei der lateinischen Sprache nicht mächtig. Unmissverständlich hieß es zu einer Caesarbiographie, sie sei «ein dilettantisches Machwerk». Gemeinsam mit Hermann Bengtson lehnte Berve $195^{2}$ ein Manu- 
skript von Ulrich Kahrstedt über das wirtschaftliche Gesicht Griechenlands in der römischen Kaiserzeit ab, da es sich um ein Lexikon der griechischen Städte und Landschaften in jener Zeit handle, aber eben nicht um eine Darstellung. Die Gliederung sei unklar und sprunghaft, alles sei im Telegrammstil geschrieben, schematisch, blutlos, dürr.

Berve empfahl lieber Qualifikationsschriften vielversprechender Nachwuchswissenschaftler für die altertumswissenschaftlichen Reihen, so etwa Reinhold Merkelbachs Dissertation «Untersuchungen zur Odyssee» (1969) und dessen Habilitation über die «Quellen des griechischen Alexanderromans» (1977), die in den «Zetemata» veröffentlicht wurden. Berve unterstützte die Übersetzung englischsprachiger Literatur, darunter das auflagenstarke Handbuch «Griechische Mythologie» von Herbert J. Rose (1955; 9. Aufl. 1997; Beck'sche Reihe ${ }^{5}$ 2012), das seine Frau ins Deutsche übertrug, sowie Victor Ehrenbergs «Sophokles und Perikles» (1956). Ehrenberg, der deutsche Emigrant, hatte 1939 kurz vor dem Einmarsch der deutschen Truppen mit seiner Familie Prag verlassen und war nach England geflüchtet. In den zwanziger und dreißiger Jahren hatte er wissenschaftlich mit Berve die Klingen gekreuzt, da man die spartanische Geschichte unterschiedlich rekonstruierte. ${ }^{161}$ Jetzt lobte Berve an dem Buch «Sophocles and Pericles», das 1954, bei Blackwell in Oxford erschienen war und das Joseph Vogt in Tübingen C.H.Beck empfohlen hatte, «die souveräne Beherrschung der Überlieferung wie der modernen Forschungsliteratur, die feinsinnige und zugleich tiefdringende Betrachtung, die Klarheit der Darstellung» und empfahl, die Übersetzung des «Kunstwerks» solle «unbedingt der Autor selbst vornehmen, dessen Muttersprache ja das Deutsche ist»; er könne sich vorstellen, dass, wenn Ehrenberg es täte, «manche Feinheiten seines deutsch gebildeten Geistes, für die im Englischen die Ausdrucksmöglichkeiten fehlen, noch eindrucksvoller herauskämen». ${ }^{162}$ Das Gutachten liest sich mit Blick auf die frühere Polemik, die Berve gegen Ehrenberg formuliert hatte, über weite Strecken als eine Art «Wiedergutmachung», die in diesem Falle umso leichter fiel, als Ehrenberg sich nach dem Zweiten Weltkrieg versöhnungswillig zeigte.

1965 unterstützte Berve die Übersetzung von Stewart Perownes Biographie des römischen Kaisers Hadrian, die erst als Sonderausgabe (1966), dann in der «Beck'schen Schwarzen Reihe» (1977) erschien. ${ }^{163}$ Anfang der siebziger Jahre empfahl Helmut Berve drei Monographien des britischen Altertumswissenschaftlers Michael Grant, deren deutsche Übersetzungen als «Beck'sche Sonderausgaben» erschienen: «Das römische Reich am Wendepunkt» (1972), «Klassiker der antiken Geschichtsschreibung» (1973) und 
«Mittelmeerkulturen in der Antike» (1974). Abgelehnt wurde hingegen «Aspects of Antiquity» (1968) des Cambridger Althistorikers Moses I. Finley. Obwohl Berves Frau 1968 für die Wissenschaftliche Buchgesellschaft Finleys epochemachendes Buch «The World of Odysseus» (1954) übersetzt hatte, bekundete ihr Mann noch Mitte der siebziger Jahre, er kenne Finleys «The Ancient Greeks» von 1963 nicht. Er habe weder das englische Original noch die französische Übersetzung gesehen, schrieb er 1974, und fügte hinzu: «Was erscheint nicht alles!» ${ }^{164}$ Negativ beurteilte Berve die Studie «Roman Imperialism in the Late Republic» von Ernst Badian, die 1968 in zweiter Auflage erschienen war. Keine Gnade fanden die zwei Darstellungen des britischen Historikers Peter Green «The Year of Salamis» (1970) und «Armada from Athens» (1970). Green sei zwar lebendig, gut lesbar, betone allerdings die Wirtschaftsgeschichte zu sehr, und er sei auf Thukydides fixiert: Thukydides aber sei «immer noch besser als Green». ${ }^{165}$ 1971 sprach sich Berve gegen Erich S. Gruens «Imperialism in the Roman Republic» (1970), Claude Mossés «Histoire d'une démocratie: Athènes» (1971) und Anthony Birleys «Septimius Severus. The African Emperor» (1971) aus. Der methodische Ansatz der letztgenannten Biographie sei fragwürdig: «Es wird in jedem Kapitel deutlich, dass Birley ein Schüler von Ronald Syme, dem bedeutendsten Althistoriker Englands der Gegenwart, ist. Die Neigung zu prosopographischer Darstellung überwiegt.» ${ }^{166}$ Der Band wurde von Ursula Pietsch abgelehnt. Stattdessen pries Berve 1972 die Kleopatra-Biographie des Vielschreibers Michael Grant als eine «glückliche Verbindung von wissenschaftlicher Genauigkeit und lesbarem Stil», wollte sie aber dennoch nicht zur Übersetzung empfehlen, da es im deutschen Sprachraum die Vita von Hans Volkmann aus dem Jahre 1953 gebe.

An dem über 70-jährigen Berve waren die neueren Entwicklungen der Alten Geschichte vorbeigegangen. Innovativen Ansätzen der angelsächsischen Forschungen öffnete er sich nicht. Stattdessen vertrat er das obsolete Konzept einer traditionellen Politikgeschichte. Auch sein einst gutes Gespür für einen rein fachwissenschaftlichen Diskurs, der einem breiten Publikum nicht zuzumuten war, verließ ihn immer häufiger. Die von ihm empfohlenen Titel von Michael Grant verkauften sich schlecht. Der Verlag ging auf Distanz. Am 19. Juli 1972 schrieb Ursula Pietsch: «Wir haben sehr lange nichts voneinander gehört, da ich Sie im Gegensatz zu den Vorjahren in letzter Zeit nicht mit dringenden Bitten um Gutachten zu behelligen brauchte. Das liegt daran, dass wir, was den Bereich der Alten Geschichte anlangt, im Hinblick auf die Beck'schen Sonderausgaben etwas zurückhaltender geworden sind. Einmal weil wir ja noch einige Grant- 
Bände zu bewältigen haben; andererseits, weil erfahrungsgemäß die Bücher, die übersetzt werden müssen, durch die anfallenden Kosten für die Sonderausgaben einfach oft zu teuer werden.» ${ }^{167}$ Auch wenn Berve noch wegen des einen oder anderen Gutachtens gefragt wurde, war offenkundig, dass sein Einfluss schwand. Stattdessen kam Moses I. Finley zu C.H.Beck. Doch diesen Paradigmenwechsel hatte eben nicht Helmut Berve initiiert.

\section{Autor und Berater: Walther Killy}

Wolfgang Beck bekundete beim Verlagsjubiläum von 1988, dass der Germanist Walther Killy mehr als nur ein Autor war; er habe als Berater den Blick der Lektoren und des Verlegers für die Krise des Faches Germanistik in den 1960er und 1970er Jahren geschärft, die sich durch ihren antihistoristischen Reflex teilweise «von den Bedürfnissen einer größeren literarisch interessierten Öffentlichkeit» entfernt habe. ${ }^{168}$ Doch der Ordinarius für Deutsche Philologie wandte sich nicht nur gegen die Vorliebe werkimmanenter Interpretationen, die eine verunsicherte Zunft nach den Verirrungen des «Dritten Reiches» präferierte; ${ }^{169}$ er stritt sein Leben lang für die historische Kontextualisierung der Literatur, kritisierte die klassischen Epochenbegriffe, wollte von einer nationalphilologischen Beschränkung nichts wissen, untersuchte nichtpoetische Werke und außerkanonische Autoren, entdeckte sein Herz für «deutschen Kitsch», ${ }^{170}$ äußerte sich zur epistemologischen Krise seines Faches und legte als einer der Ersten die nationalsozialistischen Verirrungen der Germanistik offen. Doch er wirkte nicht nur als Fachwissenschaftler. Groß war sein Einfluss als Bildungspolitiker und Wissenschaftsorganisator, als Rektor der Göttinger Universität, als Vorsitzender des Gründungsausschusses der Universität Bremen, als Herausgeber der «Exempla Classica», der «Fischer Bibliothek der hundert Bücher», der zehnbändigen «Epochen der deutschen Lyrik» und des nach ihm benannten Literaturlexikons und schließlich als Mitherausgeber der «Deutschen Biographischen Enzyklopädie».

Wie kam Killy zu C.H.Beck? Der Nachwuchswissenschaftler, der sich gerade an der Freien Universität in Berlin habilitiert hatte, wandte sich 1952 «auf Veranlassung» von Richard Newald an den Verlag. Der Berliner Germanist, der gemeinsam mit Helmut de Boor die «Geschichte der deutschen Literatur von den Anfängen bis zur Gegenwart» herausgab, hatte Killy als Autor für den achten und letzten Band des Handbuchs vorgeschla- 
gen, der die Literatur von «1880 bis zur Gegenwart» behandeln sollte. ${ }^{171}$ Killy legte erst zwei Probearbeiten vor und dann ein Exposé. Daraufhin entschloss sich Heinrich Beck im Juli 1953, den vielversprechenden jungen Dozenten unter Vertrag zu nehmen. ${ }^{172}$ Bekanntlich schrieb Killy diesen Band nie, auch wenn er in den ersten Jahren offenbar intensiv daran arbeitete, seinen Abschluss immer wieder in Aussicht stellte und Georg Sund sich 1957 beeilte, ihm die Werke von Heimito von Doderer zuzusenden, damit Killy den berühmten Verlagsautor würdigen könne. ${ }^{173}$ Die Schwierigkeiten waren immens. «Stoffliche Vollständigkeit» war nicht zu erzielen, es hieß, «eklektisch und kritisch vorzugehen». ${ }^{174}$ Welche Schwerpunkte sollten gesetzt werden? Wie musste die Gliederung aussehen? Auf welche Weise war die Zeit des «Dritten Reiches» darzustellen? Killy hatte klare Vorstellungen: Die Literatur dieser Zeit sollte «sine ira et studio als das gezeigt werden, was sie ist: ein sehr spätromantischer Nachhall, bei dem sich die ursprüngliche Weite des deutschen Gefühls nun nicht auf das Einzelindividuum, sondern auf das Volk verengt hat». ${ }^{175}$ Die Unvereinbarkeit des Ansatzes, den Killy vertrat, und der Konzeption, für die das Gesamtwerk stand, war offenkundig. Killy wollte mit diesem Band nicht weniger als «das Hauptproblem»der neueren Literaturgeschichte «in den Griff» bekommen: «Es gilt, eine wissenschaftliche Darstellung zu ermöglichen, ohne sich den daraus ergebenden, unsere eigene Existenz unmittelbar betreffenden Fragen zu entziehen.» ${ }^{176}$ Eigentlich gehe es in seiner Epoche nicht um Literatur, sondern um «kultur- und stilgeschichtliche Zeugnisse», und diesem Umstand müsse man, so schrieb er 1957, «durch ein Kapitel über Kitsch- und Gebrauchsliteratur» Rechnung tragen. ${ }^{177}$ Auf dieser Grundlage kam man nicht zusammen. Der Verlag drängte auf die Fertigstellung des Reihenwerks, Briefe wurden zwischen Walther Killy, Georg Sund und Helmut de Boor gewechselt, heftig rang man um Kompromisse. Aber schon 1960 gestand Georg Sund in einer internen Aktennotiz ein: «Offenbar hat er [sc. Walther Killy] dieses Buch in seinen Arbeitsplänen ganz nach hinten gerückt.» ${ }^{178}$ De Boor hingegen sprach sieben Jahre später von einer «Bankrotterklärung» seiner Wissenschaft, die er nicht mit seinem Namen decken könne: «Wo stehen wir, wenn kein Literaturhistoriker mehr die Kraft und die Konzentration aufbringt, eine literarische Epoche in einem literaturgeschichtlichen Handbuch darzustellen?» ${ }^{179}$

In der zweiten Hälfte der sechziger Jahre hatte sich Killy bereits durch ein anderes Projekt dem Verlag empfohlen: «Die Deutsche Literatur. Texte und Zeugnisse». Die sieben Bände, die im Mittelalter einsetzen und im 
2o. Jahrhundert enden, erschienen zwischen 1963 und 1983. Unter den Bearbeitern war mit Helmut de Boor, Albrecht Schöne und Benno von Wiese die Elite der deutschen Germanistik vertreten. Killy hatte bereits 1959 für seine Idee geworben, damals noch unter dem Arbeitstitel «Denkmäler der deutschen Poesie»: eine «wissenschaftlich begründete, übersehbare, umfangreiche Darstellung der Geschichte der deutschen Literatur in Beispielen» für «Studenten, Lehrer und Gebildete», für den Unterricht und das Selbststudium. Statt einer literaturgeschichtlichen Synthese favorisierte Killy die paradigmatische Anthologie, die Lyrik und Prosa gleichermaßen umfasste. Eine Analyse des Buchmarkts half, den Verlag zu überzeugen, sich auf das Unternehmen einzulassen: Es fehle an solchen Beispielsammlungen, folglich sei mit einer großen Nachfrage zu rechnen, betonte Killy. ${ }^{180}$ Im fast 4,00 Jahre alten Hotel «Schwan» in Oestrich wurden bei gutem Rheinwein die Regeln entworfen, nach denen das Werk angelegt werden sollte. In der Runde saßen Heinrich Beck und Georg Sund, aber auch die Kollegen, die Killy als Mitstreiter bereits gewonnen hatte: HansEgon Haß, der Sturm und Drang, Klassik und Romantik bearbeitete, und Richard Alewyn, der das 18. Jahrhundert übernehmen sollte. Eine Anordnung wurde angestrebt, «welche die wichtigsten literarischen und geistesgeschichtlichen Strömungen zusammen mit den Hauptproblemen der Zeit sichtbar macht». ${ }^{181}$

Hier wurde ein anderes Konzept als in der Literaturgeschichte von Richard Newald und Helmut de Boor vertreten, auch wenn Letzterer den ersten Band über das Mittelalter herausgab: Eine einseitig nationale Literaturgeschichte wurde für obsolet erklärt, der Vergleich mit der europäischen und der Weltliteratur gefordert sowie auf die Notwendigkeit hingewiesen, dass die Verbreiterung der Quellenbasis eine «Vervielfältigung der Gesichtspunkte» zur Folge habe. Das Charakteristische einer Epoche könne nicht mehr allein an den bedeutenden Kunstwerken abgelesen werden. Es dürfe nicht nur auf die Wiedergabe des «Besten» ankommen, «das, durch die Überlieferung kanonisch geworden, von jeder Generation neu in seinem Wert geprüft werde»; wichtig sei, «das für die Epoche Bezeichnende zu finden, in dem sich die Eigentümlichkeit des damals Alltäglichen realisiert, und das ist keineswegs immer im geprägten Stil oder im Kunstwerk von Rang der Fall». ${ }^{182}$ Killy betonte später, er habe «von vornherein einen sehr weiten und geschichtlich begründeten Begriff von Literatur gehabt», den er später nicht habe revidieren müssen, «als die 6oer und frühen 7oer Jahre auch die Germanistik freilich allzu spät und allzu theoretisch erschütterten». ${ }^{183}$ 
Wie in der Kunstgeschichte, so brachte C.H.Beck auch in der Germanistik gleichzeitig Veröffentlichungen auf den Markt, die innerhalb eines Faches divergierende methodische und epistemologische Zugänge propagierten. Der Verlag griff dabei nicht regulierend ein, sondern unterstützte vielmehr die Diversifizierung und Pluralisierung der Wissenschaftsdisziplinen. Bis 1967 lagen von Killys Anthologie sieben Bände vor, dann geriet die zügige Publikation ins Stocken. Hans Rupprich, der die Teilbände über «Spätmittelalter, Humanismus und Reformation» herausgeben sollte, starb, und seine Schülerin Hedwig Heger musste in Wien von vorn beginnen. Richard Alewyn wiederum brachte seinen Band nicht zum Abschluss, gab den Auftrag vor seinem Tod zurück, und Killy sprang ein. Doch die Sammlung war längst ein Erfolg geworden. Die Startauflage der einzelnen Bände lag zwischen 7700 und 8800 Exemplaren. Peter Wapnewski pries 1965 die beiden von Helmut de Boor herausgegebenen Mittelalterbände hymnisch in einer Rezension in der «Frankfurter Allgemeinen Zeitung». «Die sammelnde Leistung» werde «zu einem schöpferischen Vorgang durch das Arrangement.» ${ }^{184}$ Der von Albrecht Schöne verantwortete Band «Das Zeitalter des Barock», der 1963 in erster Auflage erschien, leitete eine ganz neue Phase der Forschung zu dieser Epoche ein. Konventionell war einzig Benno von Wieses Sammlung zum 19. Jahrhundert, der es ablehnte, «sich von dem Inhalt und der Gliederung der Nachbarbände beeinflussen zu lassen» und «eine Chrestomathie der deutschen Dichtung» ablieferte, aber nicht, wie Heinrich Beck bedauerte, «die geistigen Strömungen in den Vordergrund» rückte, «von denen die Dichtung jeweils getragen wird und deren Ausdruck sie ist». ${ }^{185}$

Killy war als germanistischer Autor und Herausgeber wichtig, auch wenn der Münchner Verlag keine Exklusivrechte auf den Wissenschaftler hatte, der von verschiedenen Verlagen umworben wurde. Er zählte «zu den wenigen literaturwissenschaftlichen Autoren des Verlags, die nach wie vor ein größeres Publikum» erreichten. ${ }^{186}$

Albrecht Schöne gehörte gleichfalls zu diesem kleinen Kreis. Mit dem Göttinger Gelehrten hatte Heinrich Beck zugleich den international renommiertesten deutschen Germanisten nach 1945 unter Vertrag, dessen bahnbrechende Untersuchung zu «Emblematik und Drama im Zeitalter des Barock» in erster Auflage 1964, in München erschien. Sie ist in dritter Auflage (1999) in der Reihe «C.H.Beck Kulturwissenschaft» bis heute lieferbar. Auch Schöne begleitete die Entwicklung des Verlags sowohl mit vielfältigen Anregungen als auch mit eigenen Werken und der gemeinsam mit Ulrich Joost veranstalteten kritischen Edition des Briefwechsels von 
Georg Christoph Lichtenberg (1983-92). 1976 legte er mit «Kürbishütte und Königsberg» eine innovative Untersuchung zum Barockdichter Simon Dach und zu dessen Werk vor, bei der dessen literarischer Freundeskreis im Mittelpunkt der Analyse steht, um die «poetischen Texte» sozialgeschichtlich «entziffern» zu können.

Walther Killy übernahm früh auch die Rolle des Ratgebers. Bereits im März 1956 riet er «dringend», keinen Vertrag mit dem Germanisten Franz Koch in Tübingen zu schließen, da dieser «sich mit antisemitischen Literaturdarstellungen als Historiker zu sehr disqualifiziert» habe. ${ }^{187}$ Der ehemalige Berliner Ordinarius für Literaturgeschichte hatte seit 1936 im Beirat des Reichsinstituts für Geschichte des neuen Deutschlands gesessen, hatte über «Goethe und die Juden» geschrieben (1937), den Kriegseinsatz der Germanistik geleitet und nebenamtlich als Zensor in Rosenbergs Schrifttumsamt gewirkt. Nach dem Krieg kam er in Tübingen unter, aber ohne Lehramt. ${ }^{188} 1956$ veröffentlichte er in zwei Bänden seine Darstellung «Idee und Wirklichkeit. Deutsche Dichtung zwischen Romantik und Naturalismus». Killy warnte Georg Sund eindringlich, Koch könne trotz dieser Monographie nicht die Literatur des 19. Jahrhunderts für die «Geschichte der deutschen Literatur» übernehmen. «Man würde sich sonst in der Öffentlichkeit sofort auch gegen den Herausgeber Helmut de Boor wenden.» ${ }^{189}$

Im Laufe weniger Jahre machte sich Killy unentbehrlich. Im April 1959 traf Heinrich Beck den Universitätsprofessor zum ersten Mal im Verlag, dann saß man «anregend und gemütlich» zu Hause zusammen. ${ }^{190}$ Es folgten weitere Zusammenkünfte, an denen auch Gustav End, Georg Sund, Horst Wiemer und andere Verlagsmitarbeiter teilnahmen. Am 14. April 1965 trafen sich Heinrich Beck und Walther Killy nach vorbereitenden Gesprächen zur «Schlussverhandlung» über eine Vereinbarung: Killy wurde ab ı.September 1965 als Berater für C.H.Beck engagiert, «und zwar nicht nur auf dem Gebiet der Germanistik, sondern ganz allgemein auf geisteswissenschaftlichem Gebiet». Für diese Tätigkeit erhielt er ein Honorar von monatlich 1500 DM. Die Spesen für Reisen nach München wurden vom Verlag vergütet. Dafür versprach Killy, «seine beratende Tätigkeit» beim S. Fischer Verlag aufzugeben. Mit dem Deutschen Taschenbuch Verlag, dessen Mitgesellschafter C.H.Beck war, schloss Killy «ein ähnliches Abkommen». Hierfür erhielt er nochmals 500 DM monatlich. Die Übereinkunft galt zunächst für drei Jahre. Nach 18 Monaten sollte geprüft werden, ob das Verhältnis fortzusetzen sei. ${ }^{191}$ Fortan wurde kaum eine weitreichende verlagsinterne Entscheidung in den Kulturwissenschaften getroffen, an 
der Killy nicht beteiligt gewesen wäre. Die «Killy-Konferenzen» waren Strategiekonferenzen, in denen die Programmplanung und die Unternehmenspolitik behandelt wurden. Externer Sachverstand machte sich bezahlt, und der Germanistikprofessor agierte zu einer Zeit als eine Art Managementberater, als sich McKinsey in der Bundesrepublik niederließ. Auch als Killy 1970 «aus dem Hexenkessel der Universitätsprobleme» in Deutschland an die Universität Bern flüchtete, endete seine Beratungstätigkeit für C.H.Beck nicht. ${ }^{192}$

Wie erfolgreich war Walther Killy als Ratgeber? Er äußerte sich - wie Albrecht Schöne - zu geplanten Publikationen oder potentiellen Autoren. Killy verfügte über detaillierte Informationen zu Personen und Institutionen, über Projekte und Pläne. Er unterhielt enge Kontakte zu seinen Kollegen, aber auch zu Verlagen und zur Wissenschaftsbürokratie. Über seine Netzwerke verfügte er virtuos. 1965 vermittelte Killy den Kontakt zu seinem Kollegen Peter Wapnewski, ${ }^{193}$ der in den folgenden Jahren vier Bücher zur Lyrik Wolframs von Eschenbach, zum Minnesang und über Richard Wagner bei C.H.Beck verlegte, aber auf Dauer nicht an den Verlag gebunden werden konnte. Herausgeber für die «Beck'schen Sonderausgaben» schlug Killy ebenso vor wie Autoren für die «Beck'sche Schwarze Reihe» und die «Beck'schen Elementarbücher». 1976 beispielsweise empfahl Killy seinen Kollegen Elmar Seebold aus Freiburg im Üechtland für die «Beck'schen Elementarbücher». Er sollte den Band «Etymologie» übernehmen. Killy charakterisierte ihn als «vorzüglichen Lehrer», der «bereits eine ansehnliche Produktion vorzuweisen» habe und froh sein werde, von dem C. Winter Verlag in Heidelberg «und einem holländischen Verlag», dessen Namen Killy vergessen hatte, «fortzukommen». ${ }^{194}$ Seebolds Band «Etymologie. Eine Einführung am Beispiel der deutschen Sprache» erschien 1981.

Killy war an der Diskussion und der Einführung neuer Reihen beteiligt. So plante er Mitte der sechziger Jahre nach angelsächsischem Vorbild einführende Lehrbücher für Studierende verschiedener Fächer und projektierte 1965 zunächst «germanistische Studienbücher», die unterschiedliche Gebiete wie Methodenlehre, Fachgeschichte, Poetik, Rhetorik, Verslehre, Stilkunde, Neuhochdeutsche Grammatik, aber auch antike Mythologie und Bibelkunde behandeln sollten. ${ }^{195}$ Ähnliche Bände plante man für die Romanistik und die Anglistik. Sollte zunächst Grundwissen vermittelt werden, war das übergeordnete Ziel die «Stiftung eines Problembewusstseins». ${ }^{196}$ Der Verlag sah in diesen Einführungen eine Buchform, die zwischen den Schullehrbüchern und den Handbüchern angesiedelt war und dem Unterricht auf universitärer Ebene dienlich sein sollte. Universitäts- 
lehrer wurden befragt. Wie bei der Einführung neuer Formate häufig, waren die Urteile uneinheitlich. Vertreter der älteren Generation waren in der Regel eher skeptisch, die der jüngeren eher aufgeschlossen. Der Gedanke, solche Bücher für die Geschichtswissenschaft herauszubringen, wurde von dem 40-jährigen Mediävisten Arno Borst in Erlangen begrüßt. Er empfahl, «den episch akademischen Schreibstil zu verlassen und mit Fragen zu operieren, die das Denken des Studenten anregen sollen». Der 65-jährige Hermann Heimpel, erster Direktor des Max-Planck-Instituts für Geschichte, favorisierte hingegen ein «Handbuch der mittelalterlichen Geschichte» im Umfang von zwei starken Oktavbänden. ${ }^{197}$ Die ursprüngliche Absicht, für jede größere kulturwissenschaftliche Disziplin ein «Studienbuch» vorzulegen, musste aufgegeben werden. Stattdessen wurde auf Vielfalt gesetzt. Die «Beck'schen Elementarbücher» entstanden. Neben Einführungen in Einzelwissenschaften wurde eine Vielzahl von Gegenständen traktiert. Hans Paul Bahrdts «Schlüsselbegriffe der Soziologie» (1984), Hartmut Boockmanns «Einführung in die Geschichte des Mittelalters» (1978) und Christian Wagenknechts «Deutsche Metrik» (1981) gehörten zu den erfolgreichsten Bänden der Reihe.

Killy benannte aktuelle Themen, entwickelte Konzepte und brachte Autoren ins Spiel. Die Mehrzahl der projektierten Unternehmungen war jedoch wenig erfolgreich. So diskutierte man seit Mitte Mai 1966 den Plan kommentierter Klassiker-Ausgaben, die sich an dem Vorbild der Pléiade orientieren sollten. Meist mehrbändige Ausgaben von Heine, Herder, Hölderlin, Kant, Lessing, Luther, Novalis, Voss, Wieland und Winckelmann waren beabsichtigt; zudem sollten Romane des 17. und 18. Jahrhunderts, Dramen des Sturm und Drang und ästhetische Schriften des 18. und 19. Jahrhunderts veröffentlicht werden. Im Frühjahr 1967 wollte man zehn Editionen definitiv anzeigen. Tatsächlich erschienen jedoch nur die Werke von Novalis, herausgegeben von Gerhard Schulz (1969, 5. Aufl. 2013), und Heinrich Heine, herausgegeben von Stuart Atkins (2 Bände, 1973/78). ${ }^{198}$ Auch eine Auswahlsammlung mittelhochdeutscher Lyrik, für die Killy seinen Kollegen Peter Wapnewski gewonnen hatte, wurde nie veröffentlicht.

1969/70 wollte Killy eine neue Hochschulzeitung bei C.H.Beck verlegen, die die «Deutsche Universitätszeitung» ersetzen und «die erste integrierte Institution der deutschen Wissenschafts- und Kulturpolitik» sein sollte. Heinrich Beck trat jedoch nicht in Verhandlungen ein; ihm schien das politische und finanzielle Risiko zu groß. ${ }^{199} 1971$ skizzierte Killy eine Reihe über «Methoden im Umgang mit Texten». Unter der Regie eines Herausgebers «mit fester Hand und Überschau» sollten an einem lyrischen 
und einem erzählenden Text beispielhaft sowohl «die Vielfalt und Notwendigkeit des Methodenpluralismus» als auch «die Folgen mangelhafter ideologischer Selbstkritik» gezeigt werden. Unter den Verfahren, die den Studierenden vorgestellt werden sollten, nannte Killy die werkimmanente, textanalytische, geistesgeschichtliche, komparatistische, stil- und strukturanalytische und soziologische Interpretation. Natürlich durfte auch der historische Materialismus nicht fehlen. ${ }^{200}$ Das Projekt spiegelte den neuen Methodenpluralismus, der seit den 196oer Jahren in die Deutschen Seminare und Institute Einzug gehalten hatte. Doch der Verlag setzte das Projekt nicht um: Zu weit in die neuphilologische Theoriediskussion, die bisweilen hermetische Züge annahm, wollte man sich nicht vorwagen. Erst viele Jahre später, 1993, erschien mit dem von David E. Wellber herausgegebenen Buch «Positionen der Literaturwissenschaft. Acht Modellanalysen am Beispiel von Kleists «Das Erdbeben in Chili» (5. Aufl. 20o8) ein Werk, das Killys damaligem Plan nicht nur entsprach, sondern auch als Studienbuch sehr erfolgreich war.

Anfang 1972 formulierte der in Bern lehrende Ordinarius die Optionen, die er angesichts der tiefgreifenden Veränderungen «sowohl im Bildungsbewusstsein wie im Bildungswesen» für den Verlag sah: «Eine ist die Antwort à la Rowohlt, Suhrkamp oder (bis vor kurzem) Hanser: Man drucke nur recht viel modisch Rotes, dann wird es schon gehen. Die andere ist die Antwort à la Metzler: Man mache recht viel, und dann wird unter vielem Schlechten schon etwas Gutes unterlaufen.» Er gehe davon aus, dass beide Antworten für C.H.Beck nicht in Frage kämen, dass weder «seine liberal-konservative Physiognomie» noch «das ungewöhnliche QualitätsRenommee» aufgegeben werde. Deshalb schlug er dem Juniorchef Hans Dieter Beck, der sich «sehr unzufrieden» über die Geisteswissenschaften im Haus geäußert hatte, als dritte Antwort «eine kühl rechnende, kaufmännische» vor: «Sie würde letztlich von Umsatz und Rendite ausgehen und dann radikale Konsequenzen ziehen, wenn beide für Gegenwart und nähere Zukunft nicht befriedigend sind oder zu werden versprechen.» Diese dritte Option halte er «für ehrlich, auch wenn sie außer Acht lässt, dass die nicht zu Buche schlagende Rendite $\mathrm{zu}$ ansehnlichem Teil als Goodwill auch zu Buch schlagen kann».201

Vielleicht war es Killys größtes Verdienst, den Verlag zu überzeugen, im kulturwissenschaftlichen Programm auf die soziale Öffnung der Universitäten und die Veränderungen des akademischen Unterrichts zu reagieren, die Bedürfnisse der Studierenden zur Kenntnis zu nehmen und ihre Vorkenntnisse und Fähigkeiten realistisch einzuschätzen. Studentinnen und 
Studenten mussten nicht nur in die Technik wissenschaftlichen Arbeitens und in die «Methodenlehre» eingeführt werden, sondern auch in die Bibel und die klassische Mythologie. Noch konnten sich die Geistes- und Kulturwissenschaften in Deutschland nicht mit dem Gedanken anfreunden, das Studium - wie etwa bei den Juristen und Medizinern - mit Lehrbüchern zu gestalten. Aber die von Killy mittelbar oder unmittelbar angeregten Unternehmen: «Die Deutsche Literatur. Texte und Zeugnisse» und die «Elementarbücher» ergänzten die bestehenden Reihen, die «Sonderausgaben» und die «Beck'sche Schwarze Reihe». Killy wollte den Bildungsauftrag der universitären Kulturwissenschaften zu einem Zeitpunkt verteidigen, als viele seiner Kollegen mit ihren Veröffentlichungen, die in einer esoterischen Fachsprache geschrieben waren, nur noch spezialisierte innerwissenschaftliche Diskussionen bedienten. Der Verlag wiederum verstärkte seine Präsenz auf dem Markt der einführenden Literatur; zugleich verjüngte und vergrößerte er sein Publikum. C.H.Beck ließ keinen Zweifel daran, dass man sich «aus der Reihe der nur wissenschaftliche Literatur anbietenden Häuser (Böhlau, de Gruyter, Winter usf.) herausheben» wollte, ${ }^{202}$ um in Killys Sinne «bürgerliche Bildung in einer unbürgerlichen Welt unbürgerlichen Studenten» zu vermitteln. ${ }^{203}$

\section{Die Dioskuren}

Die Zeiten von Oswald Spengler, Albert Schweitzer und Egon Friedell waren Anfang der siebziger Jahre vorbei. Man hätte den Umsatz erhöhen können, wie Walther Killy bemerkte, «wenn man aus C.H.Beck einen Econ oder Molden» gemacht hätte, was allerdings die «entsprechend strukturierten Leute» gebraucht hätte. ${ }^{204}$ Man hatte sie nicht. Vor allem aber: Man wollte sie nicht. Dennoch war es offenkundig, dass der Verlag sich verändern musste. Heinrich Beck war betagt und krank. Die Nachfolge war noch nicht eindeutig geregelt. Die alte Führungsriege im Lektorat war bereits im Ruhestand oder stand unmittelbar vor der Pensionierung. Ein Generationenwechsel war überfällig. In dieser Situation übernahmen zwei Mitarbeiter Verantwortung: Ernst-Peter Wieckenberg und Jürgen Fischer. Beide hielten, wie Walther Killy treffend formulierte, «ohne Dogmatismus an dem Niveau des Hauses» fest und vermochten den Status quo «beharrlich zu bessern». ${ }^{205}$

Jürgen Fischer war im April 1954, zu C.H.Beck gekommen. Die Liebe zum Buch prägte den gebürtigen Ostpreußen von Kindesbeinen an. Ernst 
Rowohlt, zu dem er völlig unbefangen nach seiner Schulzeit gegangen war, soll ihm gesagt haben: «Lernen Sie erst einmal die Grundlagen.»06 Also machte er in Hamburg in der Thalia-Buchhandlung von Erich Könnecke eine dreijährige Lehre als Sortimentsbuchhändler. Zuletzt leitete er die juristische Fachabteilung. Dann ging er nach München und arbeitete in der Buchhandlung Christian Kaiser am Marienplatz. Veronika Beck, die älteste Tochter Heinrich Becks, die damals ebenfalls als Buchhändlerin bei Kaiser arbeitete, stellte Fischer ihrem Vater vor, dem der junge Mann gefiel. Nach einigen Gesprächen bot er ihm eine Stelle in seinem Verlag an. Erst durchlief Fischer die verschiedenen Abteilungen, gewann das Vertrauen von Karl Schröpel, der grauen Eminenz, und arbeitete schließlich als Assistent des Herstellungsleiters Albert Heinrich.

Bald zeichnete sich Fischer durch die Optimierung von Verwaltungs- und Produktionsabläufen aus, und er zeigte Interesse für technische Neuerungen in der Herstellung der Bücher. Seine Vorliebe für Listen und Formulare brachte ihm den Spitznamen «Listenfischer» ein. Mit der Herstellung juristischer Titel hatte Fischer seine Sporen verdient. 1962 wurde er dann jedoch Herstellungsleiter der kulturwissenschaftlichen Produktion und des Biederstein Verlags. Im selben Jahr kamen die ersten Offset-Druckmaschinen in Nördlingen zum Einsatz. Eine eigene Reproduktionsabteilung wurde eröffnet. 1969 begann der Fotosatz mit der Monophoto Mark IV, und Fischer sorgte dafür, dass dieses Verfahren sukzessive für die Herstellung kulturwissenschaftlicher Titel eingesetzt wurde. $197^{2}$ erhielt er den Auftrag, auch die Ausstattung der juristischen Bücher und Zeitschriften des Verlags C.H.Beck und des Vahlen-Verlags sowie der Beck-Reihen im Deutschen Taschenbuch Verlag zu übernehmen. Typographie, Umschläge und Einbände mussten überarbeitet werden. Fischer unterstützte die Fotosatzproduktion juristischer Titel, interessierte sich für den Papiereinkauf, für die Buchbinderei sowie für Satz und Druck. 1976 lief die erste Rollenoffsetmaschine in der Beck'schen Druckerei an. Fischer verfügte inzwischen über die Prokura für den kulturwissenschaftlich-literarischen Bereich. Zwei- oder dreimal pro Monat fuhr er von München nach Nördlingen, aber auch zu Druckereien wie Appl in Wemding, die Aufträge für C.H.Beck ausführten, «um an Ort und Stelle die Termininteressen des Beck-Verlags zu vertreten, Prioritäten in beiderseits erträgliche Reihenfolge zu bringen, Ausstattungsfragen zu besprechen, sich über mögliche technische Entwicklungen zu orientieren, über deren Nützlichkeit für die Verlagsproduktion zu reden, sich über Neuaufstellungen unmittelbar ein Bild $\mathrm{zu}$ machen, und, was ihm besonders leicht fällt, menschlichen Kontakt zu halten». ${ }^{207}$ Als 1977 Albert Heinrich in 
Ruhestand ging, wurde Jürgen Fischer Leiter der Gesamtherstellung und erhielt zum 1. Juli 1978 die Prokura für den Gesamtverlag.

Eine eindrucksvolle Zahl von Büchern, die unter der Herstellungsleitung von Jürgen Fischer gefertigt wurden, wurde in typographischen Wettbewerben ausgezeichnet; sie zählen zu den «Schönsten deutschen Büchern», den «Schönsten Leinen-Bänden» und den «Schönsten Büchern aus aller Welt». Fischer war ein leidenschaftlicher Buchhersteller, ein Bibliophiler, der sich für Papierwahl, Einbandgestaltung, Typographie begeisterte. Und Jürgen Fischer machte schöne Bücher. Die von ihm als Hersteller betreute Anthologie «Die Deutsche Literatur. Texte und Zeugnisse» wurde 1965 als «Schönstes deutsches Buch» prämiert, und die gleiche Auszeichnung erhielt die Neuausgabe der «Geschichte der Stadt Rom im Mittelalter» (1978) von Ferdinand Gregorovius, in der 234, Abbildungen nach den alten Vorlagen mit großem technischen Aufwand reproduziert wurden. Doch Jürgen Fischer verstand sich auch auf Betriebswirtschaft. Er kalkulierte mit spitzem Bleistift, war sparsam und listenreich, und er verstand es zudem, die Interessen des Verlags gegenüber Papierlieferanten, Buchbindereien und mächtigen Unternehmen der Druckmaschinenbranche effizient zu vertreten. Über Jahrzehnte kooperierte er mit den Herstellungsleitern anderer Häuser, um Erfahrungen auszutauschen, aber auch, um Verhandlungsstrategien zu koordinieren und hin und wieder Preise zu drücken. Seit 1968 beteiligte sich Fischer an den strategischen «Killy-Konferenzen», und nur noch selten wurden weitreichende Entscheidungen ohne ihn getroffen.

Im Verlag zog er meist mit Ernst-Peter Wieckenberg an einem Strang. Der gebürtige Kieler, Jahrgang 1935, hatte in Göttingen und Nancy Germanistik und Romanistik studiert, 1961 das Staatsexamen gemacht und geschwankt, ob er Wissenschaft als Beruf wählen oder in das Verlagswesen wechseln sollte. ${ }^{208} \mathrm{Er}$ ging in die Buchbranche - und blieb dennoch der Wissenschaft treu. Von seinem akademischen Lehrer Albrecht Schöne wurde er mit einer Arbeit «Zur Geschichte der Kapitelüberschrift im deutschen Roman vom 15. Jahrhundert bis zum Ausgang des Barock» promoviert; sie erschien 1969 bei Vandenhoeck \& Ruprecht. Doch hatte er zunächst, im Herbst 1961, ein Angebot des S. Fischer Verlags angenommen. Dort war er anfangs zuständig für die Reihe «Exempla Classica» und lernte deren Herausgeber Walther Killy näher kennen. Seine Tätigkeit in der FischerBücherei brachte ihn mit bedeutenden Wissenschaftlern in Kontakt und bestärkte ihn, nicht im literarischen, sondern im wissenschaftlichen Lektorat arbeiten zu wollen. Doch bei S. Fischer musste er nach dem Ab- 
schluss der «Exempla Classica» im Jahr 1964, belletristische Texte lektorieren. Als dann interne Turbulenzen infolge der sukzessiven Übernahme des S. Fischer Verlags durch Georg von Holtzbrinck auftraten und die Fluktuation im Lektorat nicht mehr zu übersehen war, entschloss sich Wieckenberg, einen neuen Arbeitgeber zu suchen. Walther Killy und Albrecht Schöne rieten zu C.H.Beck. Albrecht Schöne verfasste ein kunstvolles Empfehlungsschreiben an Heinrich Beck. ${ }^{209}$ Und auch Walther Killy legte ein gutes Wort ein.

Der Verleger lud den 30-jährigen Lektor am 7. November 1965 nach München ein. Das Gespräch verlief erfolgreich, und so stellte der Verleger seinen neuen Lektor per Handschlag ein. Am Abend schrieb Heinrich Beck in sein Tagebuch: «Mittags 12.20 kommt Herr Wieckenberg aus Frankfurt, um sich bei uns vorzustellen. Er isst mit uns zu Mittag, und geht ca. 1/2 4 Uhr zu Dr. Sund. Er wirkt sehr jung, fast möchte man sagen lieb». Ich engagiere ihn für 1. Juli.» ${ }^{210}$ Heinrich Beck dachte nicht daran, dass Wieckenberg Autoren von S. Fischer mitbringen könnte. Seine Entscheidung war vielmehr dadurch motiviert, dass er die Notwendigkeit erkannt hatte, das kulturwissenschaftliche Lektorat zu verjüngen: Georg Sund war im Pensionsalter, und Hans Richtscheid stand kurz vor seinem 60. Geburtstag.

Innerhalb kurzer Zeit machte sich Ernst-Peter Wieckenberg mit seiner neuen Wirkungsstätte vertraut. Schon am 3. Juni 1967 schrieb er an den tschechoslowakischen Literaturhistoriker Eduard Goldstücker, den er von der Franz-Kafka-Edition des S. Fischer Verlags kannte: «Im Beck Verlag fühle ich mich außerordentlich wohl, umso mehr, als ich im Laufe des Jahres festgestellt habe, dass sich meine Vorstellungen von einem germanistischen Programm im Laufe der Zeit werden verwirklichen lassen.» ${ }^{211} \mathrm{Zu}$ nächst wurde er für laufende Projekte tätig: Ende 1966 überzeugte er Kurt Pinthus, sich an Walther Killys großer Anthologie der deutschen Literatur zu beteiligen. Für den von Killy selbst herausgegebenen Band über die Zeit von 188 o bis 1933 stellte der Schriftsteller seinen Essay «Zur jüngsten Dichtung» aus dem Jahr 1915 zur Verfügung. ${ }^{212}$ Doch Wieckenberg führte nicht nur Bestehendes weiter. Mit Walther Killy saß er in den Besprechungen, in denen das Verlagsprogramm diskutiert wurde. Rasch gewann er eine Vertrauensstellung und stand im ständigen Austausch mit dem Verleger. Dieser ließ seinem neuen Lektor viele Freiheiten - und nicht zuletzt die Zeit, ein größeres Netzwerk von Autorenkontakten aufzubauen.

Georg Sund umschrieb die Aufgabe, die auf Ernst-Peter Wieckenberg wartete, in der Ansprache, die er anlässlich der Feier seines 70. Geburtstags 1968 hielt: «Der zieht ja nun herüber, um meine Aufgaben zu über- 
nehmen. [...] Er soll die alten Gräben enger fassen, damit die Wasser schneller fließen, und neue Mühlen anlegen. Ich bekenne die Freude, die ich in den eineinhalb Jahren Zusammenarbeit mit ihm hatte. Aber damit will ich ihm keine Vorschusslorbeeren anheften.» ${ }^{213}$ Georg Sund, der 1922 mit einer Arbeit über «Wilhelm Raabe als Gestalter geschichtlichen Geschehens» in München promoviert worden war, meisterte mit größter Disziplin höchst eindrucksvoll ein körperliches Handicap. Er war durchaus selbstbewusst, aber nie auf forsche Durchsetzung seines Willens aus. Er legte großen Wert auf einen guten Stil und eine klare Sprache. Geschwätz verachtete, ernste Gespräche schätzte er. Aber als Lektor ergriff er kaum einmal die Initiative. Er führte Projekte aus, die an den Verlag herangetragen wurden. Ernst-Peter Wieckenberg repräsentierte einen anderen Typus: den des aktiven, planenden, Autoren gewinnenden Lektors.

Ernst-Peter Wieckenberg arbeitete von Anfang an eng mit Jürgen Fischer zusammen. So trafen sie sich beispielsweise beide am 17. Januar $1968 \mathrm{im}$ Verlag mit Hermann Müller-Karpe, dem Herausgeber des «Handbuchs der Vorgeschichte». Gemeinsam besprach man den Editionsplan; Details der Drucklegung und der Kalkulation wurden geklärt. Quasi nebenbei überredeten die beiden Verlagsmitarbeiter den Frankfurter Prähistoriker, eine «Einführung in die Vorgeschichte» für die «Beck'schen Elementarbücher» zu schreiben. ${ }^{214}$ Heinrich Beck stieß erst zu dem Gespräch hinzu, als alle wesentlichen Punkte geklärt waren. So traten Wieckenberg und Fischer als Modernisierer auf und propagierten neue Kommunikationsformen und Verwaltungsstrukturen. Lektoratskonferenzen mussten institutionalisiert und Entscheidungsabläufe im Verlag strukturiert werden. Auch in anderen Abteilungen des Hauses bestand dringender Reformbedarf: Als Wieckenberg in den Verlag eintrat, erstellte etwa die Vertriebsabteilung ihre Statistik noch mit Strichlisten. Lochkarten waren unbekannt, und erst Ende der sechziger Jahre wurde die elektronische Datenverarbeitung eingeführt.

Ernst-Peter Wieckenberg hatte eine inhaltliche Vision von einem kulturwissenschaftlichen Programm, die er in den nächsten Jahrzehnten meist im Verbund mit Jürgen Fischer umsetzte. Er hatte maßgeblichen Anteil daran, dass die Programmpolitik Ende der 196oer Jahre umgestellt wurde, als sich zeigte, dass der Verlag nicht ohne Weiteres darauf bauen konnte, dass der Zufall C.H.Beck auch künftig «gängige, für ein größeres Publikum interessante Bücher» zuspielen würde. Ältere Werke des Verlags, die als preiswerte Sonderausgaben vorgelegt werden konnten, waren kaum noch vorhanden. Allein auf die Erst- und Originalausgaben in der Reihe der «Beck'schen Sonderausgaben» konnte man sich nicht verlassen, obgleich 
es große Erfolge gab wie die «Klassiker des politischen Denkens» (1968), die Hans Maier zusammen mit Horst Denzer herausgegeben hatte. Man setzte deshalb zusätzlich auf Informations- und Lehrbücher in den Bereichen, in denen der Verlag über Sachkompetenz verfügte, und berücksichtigte in der Planung auch mögliche Kooperationen mit dem Deutschen Taschenbuch Verlag. ${ }^{215}$

Wieckenberg erkannte, dass übergreifende Kriterien für die Programmplanung fehlten; vielmehr waren Zusage oder Ablehnung eines Buches häufig von individuellen Interessen der Lektoren und des Verlegers und von schieren Zufälligkeiten abhängig. Die Absatzkalkulation spielte bereits eine gewisse Rolle, aber ökonomische Kriterien waren bisher nicht professionell in den Prozess der Entscheidungsfindung integriert worden. In diesen Punkten konnte Wieckenberg seine Erfahrungen von S. Fischer einbringen. Zunehmend misstrauisch wurde er gegen Gutachten, weil er erkannte, dass gerade in kleinen Fächern fachpolitische Aspekte bei den Empfehlungen eine Rolle spielten; so schien es ihm durchaus geraten, auch auf wissenschaftlich qualifizierte Außenseiter zu setzen. ${ }^{216}$

1971 hielt Heinrich Beck fest, dass sich selbst der Präsident der Bayerischen Akademie «liebenswürdig» über Wieckenberg geäußert habe. ${ }^{217}$ Doch im nächsten Jahr bewarb sich der in kurzer Zeit so erfolgreiche Lektor auf eine wissenschaftliche Stelle in Göttingen. Seine Bewerbung hatte indes keinen Erfolg, ${ }^{218}$ und Wieckenberg blieb bei C.H.Beck. Auch dem Werben anderer Verlage widerstand er - ebenso wie der effiziente und visionäre Herstellungsleiter Jürgen Fischer. 1974, wurde Ernst-Peter Wieckenberg zum Cheflektor des kulturwissenschaftlichen Verlagsteils ernannt. Die Dioskuren unternahmen in der Folgezeit die schwierige Gratwanderung, einerseits die konservative Tradition des Hauses zu bewahren, die in den Qualitätskriterien Gediegenheit, Konstanz und Zuverlässigkeit bestand, und andererseits die Öffnung des Verlags gegenüber neuen und aktuellen Themen, zeitgemäßen Bücherformaten und jüngeren Autoren voranzutreiben.

\section{Schwierige Nachfolge}

Heinrich Beck stand indes vor der Herausforderung, seine eigene Nachfolge zu regeln. Ihm stand noch lebhaft vor Augen, unter welch ungünstigen Bedingungen er selbst das väterliche Geschäft nach dem Ersten Weltkrieg hatte übernehmen müssen. Gustav End brachte es in seiner Ansprache 
zum 8o. Geburtstag des Verlegers auf den Punkt: «Damals war der Verlag in schwieriger finanzieller Situation, der exzellente, bedeutende, aber auch autoritäre, manchmal schwierige Vater war krank; so musste Heinrich Beck, ohne buchhändlerische und verlegerische Erfahrungen in anderen Unternehmungen sammeln zu können, in den Verlag eintreten.» ${ }^{219}$

Heinrich Beck wollte deshalb seine Nachfolge nicht dem Zufall überlassen. Die Kinder, näherhin: die beiden Söhne sollten sich auf diese Aufgabe vorbereiten. Große Liberalität kennzeichnete die Erziehung im Hause Beck. Aber in kulturprotestantischer Tradition galt Bildung als das höchste Gut, das Eltern ihren Kindern mitgeben konnten. Non scholae, sed vitae discimus, hieß die Devise auch von Heinrich Beck.

Die Frage der Nachfolge stellte sich bereits Mitte der fünfziger Jahre mit aller Dringlichkeit. 1954, waren Herzprobleme aufgetreten, und der langjährige Hausarzt hatte eingestanden, wie Heinrich Beck mit schwarzem Humor in sein Tagebuch notierte, dass er «keine Übersicht über seine Leiden» habe. ${ }^{220}$ Eine Kur zu Beginn des neuen Jahres brachte dem 65-jährigen Verleger nicht die erhoffte Linderung. Zum ersten Mal bat er Hans-Ulrich Büchting um Hilfe «hinsichtlich Erbauseinandersetzung und Testament». ${ }^{21}$ Eine endlose Serie von Geschäftsreisen und Besprechungen verzeichnet das Tagebuch Woche für Woche. Am 28. November 1955 erlitt Heinrich Beck einen schweren Herzinfarkt. ${ }^{222}$ Bis Sommer 1956 musste er sich schonen. Schmerzattacken und Herzbeschwerden quälten ihn, und mühsam war der Weg in den Verlag, «mit winzigen Schritten». ${ }^{223}$

Der älteste Sohn Hans Dieter Beck, der zunächst einige Semester Physik studiert, sich dann aber für ein Jurastudium entschieden und bereits erste Erfahrungen in der Verlagsbranche gesammelt hatte, ${ }^{224}$ trat 1960 in den Verlag ein. Während die älteste Tochter Veronika eine Familie gründete und Liselotte Medizin studierte, absolvierte die jüngste Tochter Susanne eine Lehre in der Münchner Buchhandlung Lehmkuhl. ${ }^{225}$ Der jüngste Sohn Wolfgang machte 1960 Abitur und musste sich auch Gesprächen «über seine Zukunft» stellen. ${ }^{226}$ Erst studierte er einige Semester Medizin, zeigte dann aber zur Freude des Vaters Interesse an den «philosophischen Fächern». Nachdem Hans Dieter Beck sein juristisches Examen abgelegt und seine juristische Promotion abgeschlossen hatte, kam es 1961 zu Spannungen wegen der Nachfolgeregelung. Der Vater meinte, er arbeite «scharf für seine Alleinherrschaft im Verlag».227

Im Juni 1962 streikte das Verlegerherz zum zweiten Mal. Es war wieder ein schwerer Infarkt. Albert Schweitzer gegenüber bezeichnete er sich als «alten Mann». ${ }^{228}$ An Arnold Hauser schrieb er, ihm sei «ein zweites derarti- 
ges Malheur passiert». ${ }^{229}$ Ende November 1962 riet ihm sein Arzt, für einige Zeit das Krankenhaus in Schwabing aufzusuchen. Er lehnte ab und wollte die Behandlung seiner Tochter Liselotte übertragen, die inzwischen Ärztin war. ${ }^{230}$ Hans Dieter Beck übernahm mehr und mehr Verantwortung im Verlag. Am 6. Februar 1963 ließ der Verleger Albert Schweitzer wissen, dass sein ältester Sohn «allmählich in den juristischen Verlagsteil gut hineinwachsen» werde. Aber die anderen Verlagsgebiete lägen ihm noch fern. «Wahrscheinlich wird er auch mit ihnen fertigwerden, wenn ich einmal nicht mehr da bin.» Er fügte hinzu: «Solange man aber noch lebt, kann man sich nicht totstellen.» ${ }^{251}$ In der Tat legte er großen Wert darauf, die Zügel in der Hand zu halten. Der «Schwabinger Bach» spielte zum Verlagsjubiläum 1963 mit einer neuen Belegung der Verlagsgebäude und wies dem Verleger und seinen Mitarbeitern fiktive Räume zu. Horst Wiemer fand sich im Salon, Gustav End im Diktatzimmer, Hans Richtscheid im Beichtstuhl und Carl Hoeller in der Geheimen Staatskanzlei. Andere arbeiteten im Archäologischen Institut, in der Pfälzer Weinstube und der Nervenheilanstalt. In dem geistreichen, ein wenig maliziösen Tableau residierte Heinrich Beck im «Stellwerk», Hans Dieter Beck hingegen saß im «Wartezimmer».232

Der älteste Sohn hatte es schwer, sich in dem Unternehmen freizuschwimmen. Sein Vater und die alte Führungsriege übten eine strenge Kontrolle aus. Mehrfach wurden die Aufgabenbereiche des Juniorchefs detailliert definiert. ${ }^{233}$ Der selbstbewusste und tatendurstige junge Mann äußerte wiederholt «seine Unzufriedenheit mit seiner Tätigkeit im Verlag». ${ }^{234} 1965 / 66$ ging er für einige Monate in die USA, um an der Harvard Business School zu studieren. Gleichzeitig wollte er sich mit «verlegerischen und buchhändlerischen Fragen» befassen, Erfahrungen auf dem amerikanischen Buchmarkt sammeln und sich nach Titeln umschauen, die zur Übersetzung geeignet waren. ${ }^{255}$ Sein Interesse richtete sich auf sozial- und politikwissenschaftliche Veröffentlichungen, auch von einem größeren kunsthistorischen Werk war die Rede, doch seine Vorschläge stießen nicht auf offene Ohren. Sein Werben war vergeblich.

Unterdessen durchlief Susanne Beck verschiedene Abteilungen des Verlags, und auch Wolfgang Beck, der in Göttingen bei Walther Killy und Albrecht Schöne Germanistik studierte und sich auch in den Bereichen Philosophie und Soziologie umschaute, machte sich mit dem Unternehmen vertraut. ${ }^{236}$ Georg Sund informierte ihn über die Geschäftsabläufe, korrespondierte mit ihm und ermunterte ihn, Vorschläge für das Programm vorzulegen. ${ }^{237}$ Nach seiner Rückkehr aus den USA wurde Hans 
Dieter Beck «in zunehmendem Maße an der Verlagsleitung beteiligt». Trotzdem behielt sich «der alte Herr» «die Menge der Entscheidungen» selbst vor. ${ }^{238}$ Die Spannungen wurden nicht weniger. Es kam zu Konflikten mit Lektoren und Mitarbeitern, und das Verhältnis zwischen Vater und Sohn war schwierig. ${ }^{239}$ Heinrich Beck zog Walther Killy ins Vertrauen, der ihn mahnte, die Nachfolge endlich zu regeln. ${ }^{240}$ Er drängte auf die Einbindung des jüngeren Sohnes Wolfgang, der inzwischen gleichfalls einige Zeit in Amerika verbracht hatte. Als Hans Dieter Beck 1967 den Plan fasste, Richter zu werden, handelte der Verleger. ${ }^{241}$ Man verständigte sich über einen Kommanditvertrag, den Heinrich Beck und seine beiden Söhne vor dem Familienessen am ersten Weihnachtstag 1967 unterschrieben. ${ }^{242}$

Die Leitung des Verlags lag nach wie vor bei Heinrich Beck. Hans Dieter Beck hatte das Haus verlassen, um als Jurist im Staatsdienst zu arbeiten, und Wolfgang Beck schrieb an einer Dissertation über Bestseller auf dem deutschen Büchermarkt um 1900, die Albrecht Schönes Schüler Christian Wagenknecht betreute.

Wie sehr die Zeit drängte, zeigte sich rasch: Anfang 1968 erlitt Heinrich Beck eine Hirnblutung, die ihn zu einem langen Krankenhausaufenthalt zwang, und im März des nächsten Jahres folgte ein weiterer Infarkt. Jetzt schlug die Stunde der Berater. Während Walther Killy sich zusehends für die Integration Wolfgang Becks starkmachte, drängte Carl Hoeller auf die Übergabe des Verlags an Hans Dieter Beck. ${ }^{243}$ Nach längeren Verhandlungen schlossen Vater und Sohn im Mai ein Abkommen. ${ }^{244}$ Zum 1. Oktober 1970 trat Hans Dieter Beck offiziell als persönlich haftender Gesellschafter in den Verlag ein und führte nunmehr die juristische Abteilung. ${ }^{245}$ Sofort setzte er zukunftweisende strategische Entscheidungen um: Ende des Jahres brachte Hans Dieter Beck die Verhandlungen über den Kauf des Vahlen-Verlags zum Abschluss, ${ }^{246}$ und im neuen Jahr legte er mit dem Erwerb der Fachbuchhandlung J. Schweitzer die Grundlage, dass C.H.Beck durch weitere Übernahmen einen Verbund von Fachbuchhandlungen für Recht, Steuern und Wirtschaft aufbauen konnte. 1971 setzte er gegen seinen Vater die Trennung von der Architektin Katharina Fick durch, die lange Jahre die Bauplanungen für das Unternehmen ausgeführt hatte. ${ }^{247}$

Walther Killy gab nun den Anstoß, dass der jüngere Sohn Wolfgang in Zukunft auch an den Besprechungen beteiligt und seine eigene Beratertätigkeit noch einige Jahre fortgesetzt wurde. ${ }^{248}$ Killy, der sich um das geistes- und kulturwissenschaftliche Profil des Verlags sorgte und manches abweichende Votum im Verlag als «schockierend» empfand, ${ }^{249}$ agierte auch diesmal wie ein Managementberater. Auf Politik verstand sich der 
ehemalige Rektor der Georgia Augusta und Vorsitzende des Gründungsausschusses der Universität Bremen ohnehin. Walther Killy vertrat, als der 80-jährige Verleger Heinrich Beck krankheitsbedingt nicht mehr im Vollbesitz seiner Kräfte war, die Interessen des jüngeren Sohnes, um C.H.Beck als «bürgerlichen» Verlag in einer «unbürgerlichen» Welt zumindest für die nächste Generation zu erhalten. Sein gefährlichster Widerpart im Verlag war der findige Carl Hoeller, Killys Verbündeter hingegen der charismatische Ernst-Peter Wieckenberg. Walther Killy war in dieser Phase als Unternehmensberater für C.H.Beck wichtiger denn als Programmplaner. Er half, dass der Wunsch Heinrich Becks in Erfüllung ging, seinen jüngeren Sohn als Miterben einzusetzen, «um die Geisteswissenschaften im Verlag am Leben zu erhalten», wie es der frühere juristische Lektor und Prokurist Hans-Ulrich Büchting, ein Urenkel Ernst Rohmers, formulierte. ${ }^{250}$

Bei diesen Auseinandersetzungen um die Machtverteilung im Verlag blieb Susanne Beck auf der Strecke. Sie zeigte sich keineswegs erfreut über die Entwicklungen. Schon zuvor war sie «sehr unglücklich über ihre niedrige Arbeit», die ihr im Verlag zugewiesen worden war, und führte immer wieder Klage «über ihr Schicksal als kleine Angestellte». ${ }^{251}$ Sie hatte engagiert im Unternehmen gearbeitet und auf eigene Initiative versucht, Erfahrungen in der Verlagsbranche zu sammeln und sich betriebswirtschaftliche Kenntnisse anzueignen. Ihr Wunsch, im Haus Verantwortung zu übernehmen, scheiterte jedoch an dem traditionellen Geschlechterbild des Vaters, für den a priori feststand, dass der Verlag den Söhnen übergeben werden müsse. Ihre Kritik an der Stellung einer weiblichen Angestellten - und damit an ihrer Rolle im Verlag - empfand Heinrich Beck als «das übliche Klagelied». ${ }^{252}$ Dennoch schmerzte ihn der Dissens sehr, weil er das vertrauensvolle Verhältnis zwischen Vater und Tochter belastete. Susanne Beck sperrte sich lange gegen ihren Ausschluss aus der Nachfolgeregelung, ${ }^{253}$ konnte aber letztlich eine Beteiligung an der Verlagsführung nicht erzwingen. Als Hans Dieter Beck den juristischen Verlagsteil übernahm, entschloss sie sich, ihre Tätigkeit im Familienunternehmen aufzugeben. ${ }^{254}$ Sie ging nach Zürich und begann eine Ausbildung zur Logopädin. Von dort brach die junge Frau Anfang Mai 1972 zu einer Skitour in der Nähe von Domodossola auf, von der sie nicht mehr zurückkehrte. Sie wurde am 9. Mai tot aufgefunden. ${ }^{255}$

Im Verlag kam es im Juni 1972 nochmals zu erheblichen Spannungen, als C.H.Beck vom Christian Wegner Verlag die renommierte «Hamburger Ausgabe» von Goethes Werken übernahm, die von dem Kieler Ordinarius für Deutsche Literaturgeschichte, Erich Trunz, herausgegeben worden 
war. Ein Jahr zuvor hatte sich C.H.Beck gegen den Kauf des A. G. Ploetz Verlags in Würzburg entschieden, obwohl die eingehende Prüfung der Firma und ihrer Bilanzen durch Hans Dieter Beck, Albert Heinrich und ErnstPeter Wieckenberg ergeben hatte, dass durchaus in den nächsten Jahren ein «mäßiger Gewinn» zu erwarten war. ${ }^{256}$ Der «Große Ploetz», das berühmte historische Nachschlagewerk, interessierte Heinrich Beck nicht sonderlich. Die Entscheidung überließ er seinem älteren Sohn, «der Jurist ist und dem es nicht an Unternehmungslust gebricht». ${ }^{257}$ Doch bei der Goethe-Ausgabe lagen die Dinge anders. Heinrich Beck wollte die «Hamburger Ausgabe» in seinem Haus, weil er am Ende seines Lebens in den erlauchten Kreis der Goethe-Verleger eintreten wollte. ${ }^{258}$ Der Herausgeber Trunz wiederum, den sowohl Walther Killy als auch Ernst-Peter Wieckenberg von seiner Mitarbeit in der Reihe «Exempla Classica» kannten, wollte seine Edition nicht bei einem fachwissenschaftlichen, sondern bei einem Publikumsverlag aufgehoben sehen, damit sie zahlreiche Leser erreiche. Killy hatte zwar, nicht zuletzt aus politischen Gründen, Vorbehalte gegen Trunz, bestärkte aber ebenso wie Wieckenberg Heinrich Beck, diese Ausgabe zu übernehmen. ${ }^{259}$ In dem ersten Entwurf des Vertrags erklärte sich C.H.Beck Anfang Juni zunächst bereit, zusätzlich zu dem Kaufpreis - der sich nach der vom Christian Wegner Verlag bereits vorgelegten Dokumentation der Herstellungspreise für die Bestände an gebundenen Bänden und Rohbogen berechnete - einen Betrag in Höhe von go ooo DM zu zahlen, der sozusagen das Renommee und den künftigen Wert der Ausgabe spiegeln sollte. Hans Dieter Beck widersprach dieser Regelung und reduzierte die Summe auf 75000 DM. ${ }^{260}$ Heinrich Beck notierte in sein Tagebuch, dass sein ältester Sohn «ein niedrigeres Angebot für die Goethe Ausgabe an Wegner» durchgesetzt habe. ${ }^{261}$

Am 2o. Juni flogen Hans Dieter Beck und Jürgen Fischer nach Hamburg, um Einsicht in die Verträge zu nehmen und sich «über den Zustand der Rohbestände sowie über die tatsächlich vorhandene Menge von Filmen, Druckplatten usf. zu informieren». ${ }^{262}$ Jürgen Fischer hatte von Heinrich Beck den Auftrag, die Ausgabe für C.H.Beck zu sichern. ${ }^{263}$ Der Herstellungsleiter fertigte eine erste Bestandsaufnahme an, die Heinrich Beck zwar veranlasste, die Akontozahlung auf den noch exakt zu ermittelnden Kaufpreis von 300000 DM auf 200000 DM zu senken, aber den zusätzlichen Betrag bei 90 ooo DM zu belassen. ${ }^{264}$ Der «alte Herr» hatte sich durchgesetzt. Am 28. Juni schrieb er an Erich Trunz: «Ich hätte es nicht gewagt, dieses große Werk für meinen Verlag zu erwerben, wenn ich nicht großes Vertrauen in Sie setzte.» Er freute sich auf die Zusammenarbeit. ${ }^{265}$ Auch 
als Kaufmann hatte Heinrich Beck richtig entschieden: Die «Hamburger Ausgabe» wurde als Sonderausgabe, in Dünndruck und in Leder zu einem großen und langfristigen Erfolg für C.H.Beck. Nach dieser Episode zweifelte er nicht mehr daran, dass die Zukunft des kulturwissenschaftlichen Verlags auf den Schultern seines jüngeren Sohnes Wolfgang ruhen würde, der Ende 1972 seine Dissertation aufgeben und sich ganz dem Verlag und der «geisteswissenschaftlichen Abteilung» widmen musste. ${ }^{266}$ Heinrich Beck starb am 25. April 1973. Am selben Tag trat Wolfgang Beck durch testamentarische Verfügung als persönlich haftender Gesellschafter gleichberechtigt in das Unternehmen ein. 
https://doi.org/10.17104/9783406654015-515, am 26.04.2023, 10:34:53

Open Access - (c) EY EY - http://www.beck-elibrary.de/agb 